\title{
Medios de Comunicación en El Salvador, entre transculturizaciones y programación con antivalores
}

\author{
Media in El Salvador, among acculturation and programming with anti- \\ values
}

\author{
MEd. Fidel Arturo López Eguizábal \\ Universidad Francisco Gavidia (Salvador) \\ flopez@ufg.edu.sv
}

Recibido: 10 de enero de 2013

Aceptado y Publicado: 10 de marzo de 2013

\begin{abstract}
Resumen
En esta investigación, se presentan los efectos que realizan los medios de comunicación social en los seres humanos. Además, se estudian los antivalores y trasculturización que transmite la programación y se analizan los estragos que ha ocasionado: inventan héroes falsos a la hora de disfrazar la realidad, bombardean cada vez con más consumismo y el ocio resulta ser la principal actividad diaria. Convierten a los infantes y jóvenes en personas con conductas esclavizantes a base de mensajes subliminales cargados de pornografía, violencia y antivalores.
\end{abstract}

\begin{abstract}
In this investigation, are the effects social media make in the majority of people. Also explores the values and acculturation that transmits the programming and discusses the havoc that has caused: they invent heroes fake when it comes to disguise reality, bombarded each time with more consumerism and leisure time turns out to be the main daily activity. They become infants and young people with enslaving behaviors based on subliminal messages full of pornography, violence and negative moral values.
\end{abstract}

Palabras Clave: transculturización; amarillismo; estereotipo; censura; antivalor; consumismo.

Key Words: acculturation; sensationalism; stereotype; censorship; anti-value; consumerism. 


\section{Introducción}

Algunos medios de comunicación y programas, son una fuente anticultural en nuestro país, excepto en aquellos hogares recatados que hacen caso omiso a sintonizar programas fuera de orden, con malas expresiones, programas no propios a nuestra cultura, entre otros aspectos. Para analizar el entorno salvadoreño, se analiza primero publicidad a nivel mundial y estereotipos y culturas copiados.

Se ha buscado analizar de muchas maneras los estragos que han ocasionado en la sociedad los medios de comunicación, sus héroes a la hora de disfrazarnos la realidad, de convertirnos en consumistas y llevar entretenimiento a miles de personas y convertir el ocio como objetivo principal. Los medios de comunicación social transmiten estereotipos falsos a la sociedad, convierten a los infantes en personas con conductas esclavizantes, con antivalores e influencias negativas. A los jóvenes les transmiten mensajes subliminales cargados con pornografía, violencia y deshonestidad. La publicidad está cambiando sus estereotipos, enseñándonos otro esquema de digerirlos.

Los medios de comunicación son así, más si se trata del nuevo miembro en el hogar como lo son las redes sociales. Los medios de comunicación social (MCS) son, en algunas ocasiones bofetadas a la realidad cultural. ¿Quién está a cargo de vigilar todos los cambios culturales en los medios de comunicación en El Salvador?

El Salvador es un país subdesarrollado y, con respecto al consumo de medios de comunicación, las autoridades pertinentes, deberían, de adoptar una postura en que se consuman programas culturales y con valores, para poder avanzar hacia una nueva diáspora en la sociedad.

\section{Metodología}

El trabajo realizado, parte desde el año 2004, en donde realicé una encuesta a niños en la cabecera departamental de EI Salvador (Santa Ana); además se realizó otra encuesta en los municipios de San Salvador en el año 2012. La recopilación de datos la realicé, gracias a los alumnos de la licenciatura en Relaciones Públicas y Comunicaciones de la Universidad 
Francisco Gavidia. Las encuestas en la segunda investigación de campo, se tabularon y se analizan, presentándose de gráficos pastel.

Se ha tabulado la segunda encuesta para analizar de mejor forma, cómo es el consumo de los medios de comunicación y los tipos de programas predilectos.

Se incorpora imágenes de la encuesta realizada, de los videos y noticias investigados en el portal "Youtube". También se analizan los periódicos salvadoreños. Se mezcló el trabajo en una investigación de campo con herramientas de recolección de datos como el cuestionario, el cual se estructuró con preguntas cerradas.

Los aspectos cualitativos, se entrelazan con una encuesta realizada en Facebook, en donde se interrogó sobre qué opinan sobre dos programas televisivos.

Se incorpora ejemplos de expresiones soeces que realizan locutores y presentadores de programas de concursos y entretenimiento y, se contextualiza las teorías sobre la influencia de los medios de comunicación social, ejemplos a nivel mundial y nacional.

En la investigación, no menciono a todos los medios de comunicación en El Salvador, nada más puntualizo o hago referencia en los programas con antivalores.

\section{Los Medios de Comunicación Social en El Salvador: un panorama cultural.}

Con respecto al trabajo que realizan los medios de comunicación, ha sido, desde que se crearon en El Salvador, copias fieles de otros países. Programas enlatados, que se han adaptado a nuestra "idiosincrasia". Boris Eserski, fundador de la televisión salvadoreña en 1956, es el pionero en llevar a través de "la pantalla chica", los objetivos principales de la televisión: entretener, educar y culturizar. Sin embargo, esa misión cambió, ya que tenemos una programación con locutores mal criados y programas de televisión anticulturales.

En El Salvador, las personas consumen "programación en cable", las cadenas: TV Azteca, Televisa, Venevisión, Telemundo, entre otras, son las preferidas, ya que, las telenovelas con clasificación "prime time" son las que dominan los rating de audiencia ¿Ese es el tipo de cultura que consume el salvadoreño promedio? 
La radiodifusión está llena de locutores mal hablados, de aprendices que se la pasan durante el turno burlándose del mismo salvadoreño, cuentan chistes eróticos, y de esa manera cumplieron su turno. Sin embargo, cada quien con sus gustos y preferencias, aunque en el dial, la mayoría de radios presentan una programación orientada a los jóvenes. Son pocos los programas culturales en el país.

Personajes, programas de entretenimiento, "tolkshows", etc., han sido parte de la cultura salvadoreña. Los primeros programas, eran culturales, de entretenimiento $y$, en ningún sentido falto de valores. Algún chiste de mal gusto o de doble sentido eran los que se escuchaban en las radios y se actuaban también en la televisión.

"Los medios de comunicación social salvadoreños, desde sus inicios han abierto la cultura salvadoreña a otras culturas, a través de toda la variedad de programas importados...Los niños, jóvenes y adultos han tomado como modelos a personajes de la televisión, de la radio y los periódicos, quienes nos han influenciado en las formas de pensar, sentir y obrar".

Omar Rincón, un comunicólogo crítico hacia la publicidad y los medios de comunicación, visitó El Salvador y manifestó en un taller de comunicaciones realizado en la Universidad Centroamericana "José Simeón Cañas" que en el país somos consumistas, además, expresó que en las calles de la urbe salvadoreña, observó bastantes vallas publicitarias, se sorprendió de la infinidad de textos publicitarios.

Esto nos hace recapacitar que, esa es parte de la cultura mediática, los mensajes semióticos son variados en todas las calles de la capital, evidencian que: no hay supervisión de parte de las autoridades del Gobierno y, somos una sociedad consumista. La regulación de la cultura de anunciar de todo. La Asamblea Legislativa y autoridades encargadas, tienen la misión de regular la publicidad en las calles, esa cultura, nada más la practicaron pocas empresas como Bayer de El Salvador, quienes desinstalaron un logotipo gigante. La idea era no perturbar a los volantes con tanta basura visual.

A los salvadoreños, les gusta el espectáculo barato, las obras de arte, las obras teatrales y todo que sea de buena cultura, queda en segundo plano. Le gusta ir al cine, caminar en los pasillos de los centros comerciales, invertir el tiempo en los medios de comunicación y, ahora el Facebook, como principal atracción. 
Los periódicos, son los que nos legan cargados de información, pero en muchas ocasiones, más cargados de publicidad, que de información positiva. Excepto el periódico Co Latino, el cual, por tener un pensamiento izquierdista, ha sido ignorado por los anunciantes o propietarios de las mejores empresas. Cuenta con poca publicidad.

Los periódicos, son los que más tratan de culturizar con sus secciones diversas como: salud, cocina, panoramas culturales y turismo. Lo demás, son informaciones variadas. La Prensa Gráfica es un referente, el cual, se consolida como el mejor paródico en el país y, cuenta con secciones en donde culturiza, ejemplo los boletines que ayudan a aprender a leer a analfabetas. Lo mismo hace El Diario de Hoy, con sus secciones culturales y educativas.

¿Será que el salvadoreño tiene amnesia cultural? ¿O se cree culto el salvadoreño al ver tantas telenovelas y escuchar programas basura?

\section{Los shows radiales al estilo amarillista y anticulturales}

Según la Real Academia Española transculturización es: "Recepción por un pueblo o grupo social de formas de cultura procedentes de otro, que sustituyen de un modo más o menos completo a las propias".

¿A quién le gusta mal educarse con el programa de Salvador Alas "La Choly"? Más de alguna vez hemos sintonizado radios que difieren de la "Época de oro de la radio salvadoreña". Ya no hay voces graves, programas culturales y educativos como antes. Actualmente, la diáspora radial está repartida en un pastel con más radios de corte amarillista, con lenguajes vulgares y fuera de contexto, sin guiones y con vocabularios que harían levantarse de la tumba a muchos académicos que defienden la lengua castellana.

Escuchar a La Choly por las mañanas, de lunes a sábado de seis a diez de la mañana, en radio Scan 96.1FM, es una total diversión, envuelta entre una gama de shows y personajes que hacen pensar que nuestra cultura es así, con antivalores y con malas expresiones y sin sentido, sin programas educativos, etc. Hasta estudiosos se despojan de su sagrado tiempo para escuchar este antimodelo de programa.

En años remotos la programación era más "intelectual", cultural y con locutores estudiados. Actualmente cualquiera puede hacer radio o locutar durante horas. Lo importante es llenar el espacio y ganar rating para hacer más dinero para el propietario del medio de comunicación ¿Es eso lo que queremos enseñar a los alumnos de comunicaciones en las universidades? 
¿Los aspectos éticos se reflejan en este tipo de programas? ¿Piensan en generar dinero o nada más un simple rating? ¿Son nuestros hijos los que tienen que soportar también este tipo de programas?

Incorporo un texto de los mensajes del programa La Choly, el cual extraje de Youtube "papirrín, contéstame gordo, soy tu dama, soy tu puta contéstame, soy tu mujer contéstame "c" en el tráfico de la mañana presentamos el maravilloso mundo de las ratas, si por una fina cortesía de la calavera de tu mamá..."

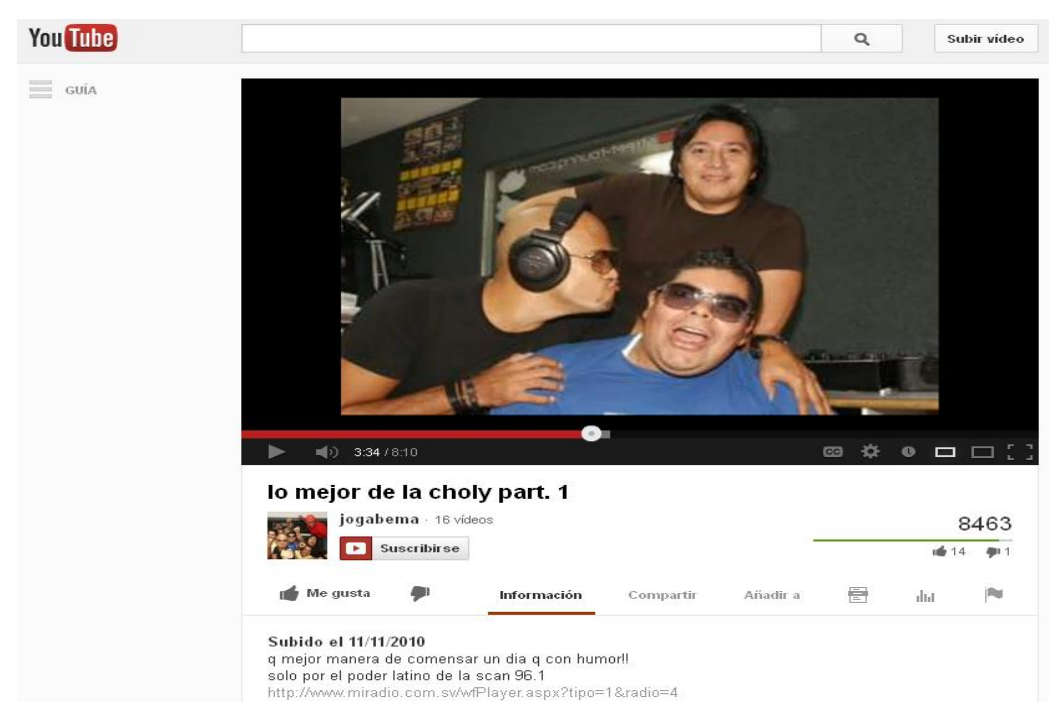

Fuente: http://www.youtube.com/watch?v=ildjG5vHpds

¿El Ministerio de Gobernación de El Salvador regula este tipo de programas? ¿Es parte de la libertad de expresión o la demasiada libertad de expresión? ¿Es nuestro país referente de programas llenos de vulgaridad sin control?

Conste, que solamente se analiza un extracto de uno de los programas con mayor rating o audiencia en El Salvador. Quizá, lo positivo del programa es que mencionan verdades de políticos y en ocasiones han colaborado en catástrofes. Sin embargo, este programa así como otros, es para analizarlos y abrirles los ojos a los padres de familia, Ministerio de Gobernación, Ministerio de Educación, iglesias y el Gobierno. No podemos estar escuchando mensajes tergiversados y llenos de mensajes pornográficos, violencia, etc. Recordemos que violencia genera violencia. 
Cuando trabajé en Radio Stereo Club en la década de los años noventa, me encontré con una radio que contaba con el formato "adulto contemporáneo", en su interior aun se trabajaba con: Rill, DAT, casetes, Cd's, etc. No había computadora y no nos permitían tomar el control de la radio. Es una radio con formato adulto joven, en donde solamente los experimentados y privilegiados o expertos podían locutar o dar por lo menos la hora.

El esquema radial ha cambiado en tecnologías y en programación, además, las letras de canciones denigran como el "perreo y reggaetton". Es creíble saber que muchos jóvenes en pleno siglo XXI manifiestan que es mejor las letras y canciones de las épocas 1980 a 1990. La programación radial y televisiva no contenía mensajes vulgares, no se programaban mensajes con doble sentido. Los estudiantes de comunicaciones o alguien que nació para estar en el mundo radial, tienen en algún momento el sueño de tener su propio programa, hablar sobre temáticas científicas, culturales, políticas, entre otros. Sin embargo, el objetivo de muchas radios es de penetrar en la mente de las personas, hacer pensar a los radioescuchas o engañar a la audiencia al estilo de Orson Welles.

La Asociación Salvadoreña de Radiodifusores (ASDER), tiene la misión de: "Promover los valores que desarrollan la radio y televisión privada, libre e independiente a través de la incansable defensa del sistema de libertades. Entre uno de sus objetivos está realizar todas las actividades que se deriven de la naturaleza de la Asociación y procurar su desarrollo, capacitación cultural y prosperidad".

Por lo tanto, existe quien supervise la programación radial en el país, pero algunas radios no acatan las reglas. Un aspecto es la libertad de expresión y otra el libertinaje de locutar aspectos que van en contra de principios morales o culturales.

"Todo cambia" como dice la canción de Mercedes Sosa, pero la transculturización hace que adoptemos estereotipos y se permite a los medios que sean parte de nuestras vidas, los cuales deben estar vigilados..."Los observatorios de medios se concentran en los contenidos y desde allí analizan las representaciones sociales y las morales públicas comunicadas; sobre todo aquellos contenidos activados por los movimientos sociales como lo son la niñez, los derechos humanos, los estereotipos de la mujer, lo sexual, lo medio ambiental, y ese abstracto llamado minorías; todo eso denominado socialmente deseable aunque no cotidiano. Se parte del criterio de que los medios de comunicación son algo muy importante 
para la sociedad, por lo tanto debe ser vigilado y controlado (y ojalá castigado). Así, un grupo humano (movimiento social, academia, educadores o políticos) que se siente superior ética y conceptualmente quiere vigilar, controlar y castigar a quienes informan y entretienen".

En el país, las radios que siempre están en los ratings y rankings, son las que están llenas de vulgaridades y programas para las grandes masas. Sintonizar la radioemisora YXY 105.7 FM, es otro ejemplo de radioemisoras, en donde, nada más se necesitan unos minutos para analizar que no es apta para niños o personas educadas.

Otro programa, en donde hay chistes de doble sentido y en ciertas ocasiones aspectos vulgares de Roberto Reyes con el personaje "El Primo Chomo" Programa que se transmite todos los días por Radio Fiesta desde las cinco de la mañana. Su formato es al estilo campirano, un personaje que tiene un acento al estilo salvadoreño y un lenguaje peculiar, su cabello alborotado, botas y un traje con conceptos del típico salvadoreño. Su programa divierte, sin embargo, sus chistes de doble sentido no son aptos para menores de edad.

En una capacitación que asistí sobre "Atención a las entrevistas hacia los medios de comunicación", el periodista de Canal 2 de TV, Alex Pineda, le preguntó a una locutora que labora en radio católica Radio Paz ¿Por qué en su programación permitían canciones con formato reggaetonero?, la locutora mencionó "El mensaje es la letra de la canción, lo que queremos es que los jóvenes reciban a través de este tipo de música el mensaje espiritual". Los mensajes a través de la música también se disfrazan subliminalmente. No importa sean letras religiosas. El periodista Lemus, le corroboró a la locutora que la música o la tonada incitan al sexo y, por lo tanto, el tratar de incorporar este tipo de formato a través de un tipo de música es confundir a los creyentes o religiosos.

Lo anterior se analiza siempre en una transculturización hasta en lo religioso. Ese morbo, es el que hace que muchos programas se mantengan al aire. ¿Está el Ministerio de Gobernación regulando la programación?

Según el periodista y catedrático Wilber Gómez manifestó: "El hombre debe moverse por la fe y no desvirtuarla por querer mantener la feligresía" aseveración acertada, ya que, no se debe aprovechar esos ritmos nada más para aspectos de rating. 
¿Cuántas radios están impactando con mensajes con antivalores? En la encuesta que realicé, los entrevistados, fueron claros al decir que los programas "chabacanes" o mal criados, son sus preferidos.

Lo anterior, me hace recordar lo que mencionó Mario Vargas Llosa en la entrevista realizada por Andrés Oppenheimer, en el programa "Oppenheimer Presenta", en donde Vargas Llosa recalcó que los medios de comunicación, en vez de informar, están sirviendo para hacerse chismosos. En la entrevista, Vargas Llosa llegó a presentar su último libro "La Civilización del Espectáculo", en donde claramente refleja: "Las personas están perdiendo los valores culturales y que los medios de comunicación manipulan en diversos sentidos". Un claro ejemplo es la cultura mediática, la cual transforma en robots o maniquís a los seres humanos cuando van al estadio a apoyar a su equipo. Y, así, hay variedad de ejemplos, en donde los aspectos culturales están perdiéndose.

También están de moda los canales de música, todo el día transmiten videos de cantantes de "perreo" y "reguetón". Cuántas veces hemos verificado en Star Channel programación musical, en donde la sensualidad, es la primera carta a presentar. Se evidencia con mensajes de textos enviados por teléfonos celulares, en donde se leen leyendas tales como: "hombre busca a hombre", mujer quiere aventura con chica joven", "hombre activo busca pareja", etc. ¿Cuántos niños y niñas están viendo esos mensajes, cuántas personas estudiadas o en su sano juicio saben que esos mensajes son parte de una antieducación?. En los canales de cable, existe, una variedad de canales musicales. Ahora no es usual ver espectáculos desvalorizados, sin ética y con la única intensión de vender. La música ha cambiado, sus letras manifiestan cada vez: Más odio, desunión familiar, erotismo, consumismo, etcétera. Los grupos musicales y cantantes como: Calle 13, Molotov, entre otros, son pioneros en llevar mensajes con malas expresiones a los radioescuchas y telespectadores. Las letras de canciones con antivalores, hace conductas hostiles, las letras de las canciones convierte a personas en antisociales y con una personalidad agresiva.

"El presidente del Instituto Cubano de la Música (ICM), Orlando Vistel, advirtió que el reggaeton (que deriva en el baile llamado "perreo") dejará de escucharse en lugares públicos de la isla, porque el gobierno lo consideró como una expresión "vulgar y mediocre". En entrevista con el diario Granma, Vistel consideró que "ni la vulgaridad, ni la mediocridad podrán mellar la riqueza de la música cubana”.[1] 
Ahora bien, acá se ha analizado más aspectos salvadoreños, debemos ver de dónde vienen estos mensajes transculturizados. Punto que nos incumbe, ya que al final vemos resultados como: drogadicciones, pornografías, embarazos precoces, desintegraciones familiares. ¿Es recomendable copiar culturas de países desarrollados? ¿Qué beneficios les dejan a los niños y jóvenes?

Deseo acotar una experiencia al escuchar a un pasajero en un autobús, quien a pesar de ir un poco ebrio, manifestó lo siguiente: "Esa música es mala, ya que incita al sexo, esos movimientos eróticos que se observan en los videos, esa música no la permito que la escuchen mis hijos, es dañina para la salud mental...por eso hasta embarazadas salen las cipotas (jovencitas) al excitarse con esa música". Aspecto que se aplica en sociedades consumistas Recientemente, en Cuba prohibieron ese tipo de música, manifestando que las letras de las canciones contienen malas expresiones y antivalores.

\section{Estudio de preferencias en los Medios de Comunicación Social}

\section{a) Encuesta realizada en colegios de Santa Ana}

Realicé una encuesta a cincuenta alumnos en la ciudad de Santa Ana en el año 2004, en donde el objetivo era saber el tipo de programación que miraban los niños en la televisión, la investigación se centró en el área urbana de la ciudad y se arrojó las encuestas en dos colegios. Los niños cursaban: primero a cuarto grado. Los colegios encuestados fueron: Colegio María Auxiliadora y Colegio Bautista. Las edades de los niños comprenden entre 7 a 11 años. Nada más fueron cinco interrogantes, la principal fue: ¿Qué programas mira en la televisión?. La mayoría se refirió a programación en cable.

La programación para niños en cable, que es un aproximado del $70 \%$ que cuentan, con esta conexión, tiene una variedad de programas: Bob El Constructor, Dora La Exploradora, Barney y sus amigos, entre otros, fueron los preferidos. Hay programación eminentemente educativa y es la que deberían los padres estar pendientes que consuman sus hijos. En kindergarten, las maestras toman de referencia este tipo de programas educativos. Un punto principal, es que los alumnos encuestados son de colegios y, por ende, los alumnos de institutos o escuelas públicas no tienen en su gran porcentaje programación en cable. 
Algunos niños, manifestaron que les gustaba mirar televisión con sus abuelos, ya que, les permitían de vez en cuando mirar telenovelas. ¿Quién vigila entonces a los niños?

Mi propósito en este trabajo fue, identificar los programas culturales que se transmitían en cable y las preferencias hacia ellos. Además, pregunté ¿Cuántas horas mira televisión?, quienes contestaron en un $80 \%$ que cinco horas al día, luego de hacer las tareas y, esa cantidad aumentaba si estaban de vacaciones.

Comprobé que los niños, cuando son educados en centros escolares religiosos, son más educados y más vigilados a la hora de consumir medios de comunicación, en especial el televisivo.

No es necesario tomar el punto que siempre se ha tenido de la influencia negativa de los medios de comunicación, en especial hacia la niñez o incorporar anécdotas del niño que se tiró de un edificio, porque se creía Superman o El Hombre Araña.

Cada niñez y juventud es diferente, así los medios de comunicación cambian la programación para estar siempre como "aguja hipodérmica" o "bala mágica" inyectando una variedad de programación.

Yo crecí mirando programas inocentes o sin tanta violencia, entre esos programas están: La Hormiga Atómica, Heidi, Chespirito, etc. Una programación sana, que se disfrutaba en televisores blanco y negro ¿Siempre dejamos a los niños ver esa programación sana? ¿Han cambiado los programas en pleno siglo XXI?

Según Tomás Fernández García y Agustín García Rico, los medios nos influencian de diferentes formas, a saber:

- Reflejar fielmente el mundo empírico en el que se ejercen las influencias de los medios.

- Determinar el grado de sensibilización que la población estudiada tiene sobre los medios de comunicación.

Además, refuerza que no se debe presuponer determinados efectos, se tiene que verificar la manera en cómo influencian a la sociedad. 
La programación es variada y llena de asesinatos, violencia y pornografía ¿Son los padres, el ente educador hacia los niños y jóvenes en indicarles y educarles sobre el tipo de programación que tienen que ver? Se han realizado cientos de estudios sobre los efectos e influencias de los medios de comunicación, esos estudios de audiencias, sirven para comprar aspectos nocivos y alertar a la sociedad.

b) Encuesta sobre preferencias de medios de comunicación en San Salvador y su influencia en antivalores y la preferencia de programas educativos.

La encuesta fue realizada a 200 personas en San Salvador (Apopa, Mejicanos, Ayutuxtepeque, San Martín, San Marcos, Tonacatepeque, Ciudad Delgado, Ilopango, Nejapa, Soyapango, Cuscatancingo y San Salvador). El objetivo fue, conocer las preferencias de los televidentes, radioescuchas y lectores acerca de la programación en las ciudades principales de la capital salvadoreña. Fueron once interrogantes. Además, de conocer qué hacen las autoridades del Gobierno para censurar o controlar la programación en los medios de comunicación. El público encuestado fue de 98 personas, sexo femenino y 102 del sexo masculino. Las edades oscilan entre 18 a 46 años. La ocupación según la encuesta es: Estudiantes 100, empleados: 73 y profesionales: 27.

La primera pregunta se identifica con la temática central de este ensayo "los antivalores en los medios de comunicación". En este caso la pregunta reza de la siguiente manera: ¿Está de acuerdo en que se transmitan programas con antivalores en el país?

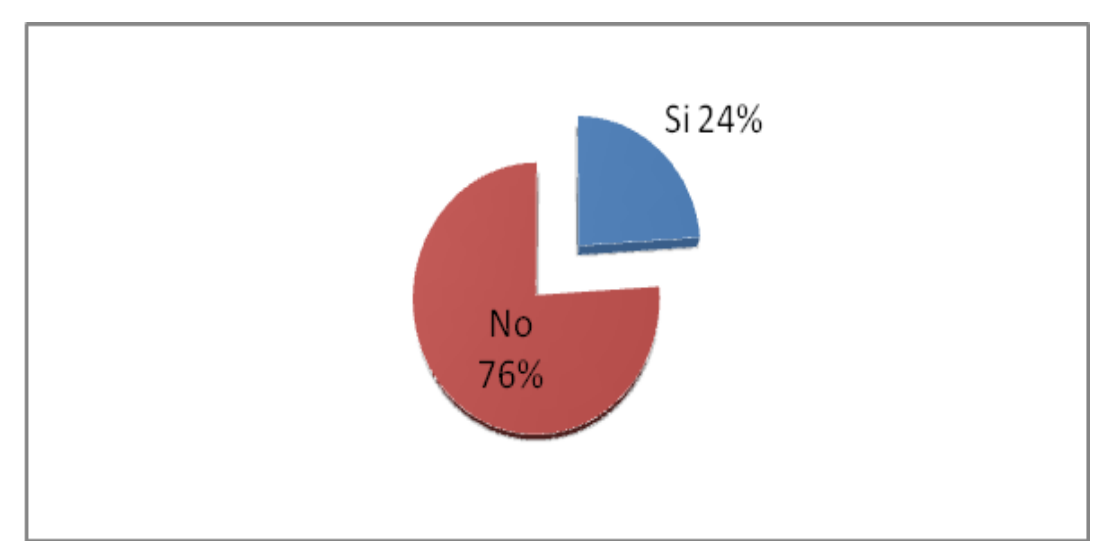

Fuente: Investigación propia 
El 76\% respondió que no está de acuerdo y el 24\% está de acuerdo. Según la investigación, la interrogante tiene un complemento ¿Por qué?, en donde las respuestas se enfocaron en que denigran a las mujeres, la música que programan no es adecuada, no hay control en la programación y no educan; además, el programa de La Choly, fue citado como antimoral.

Los resultados de la encuesta, depende del nivel de educación de los entrevistados. Se deja claro, que a este sector de personas, no les interesa mucho culturizarse.

Somos seis millones y medio de habitantes y, educar con buenas costumbres y valores a todos es difícil. Ahora, tenemos que enfrentar a este tipo de programas.

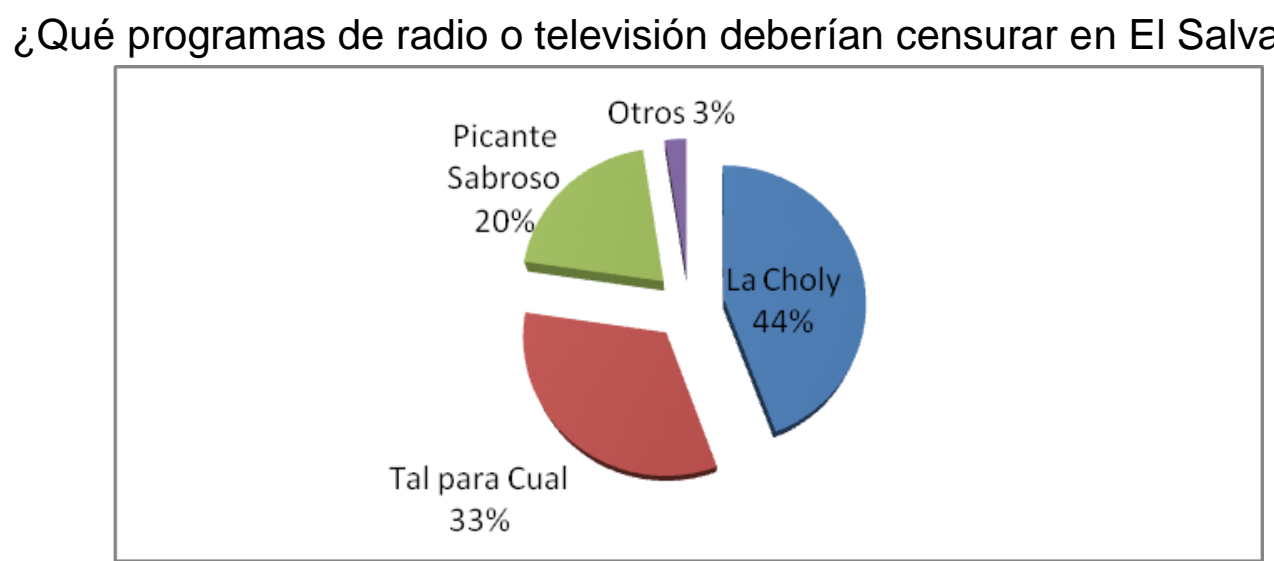

Fuente: Investigación propia

¿Qué es censura?, es simplemente quitar o eliminar. El mismo Salvador Vásquez, manifestó en un taller de Radio en la Universidad Francisco Gavidia que el presidente de El Salvador, Mauricio Funes, le habló por teléfono manifestándole que debería censurar ese programa. La libertad de expresión en el país, es un punto importante, por el cual estos programas siguen siempre con ese formato.

El análisis quedó de esta manera: Un 44\% de los encuestados manifestó "La Choly", 33\% "Tal para Cual", $20 \%$ "Picante Sabroso" y $3 \%$ otros. Se analiza que el programa que se transmitido de lunes a sábado, de seis hasta las diez de la mañana La Choly, el cual no es tan grato escucharlo para los habitantes de San Salvador, es el favorito. Me imagino que así lo han de manifestar muchos en el país. ¿Pero qué tiene de malo? Su guión mañanero está compuesto por burlarse de los políticos, parodias, chistes de doble sentido, malas palabras o expresiones no aptas para infantes, etc. Sin embargo, según las personas a la hora de 
contestar las encuestas manifestaban que: ese programa les gusta, ya que es "vulgar" y dicen chistes de doble sentido y no les gustaría que desapareciera.

Se comprueba que cada país se inyecta veneno con este tipo de programas porque así lo desea, la sociedad latinoamericana y salvadoreña, nos está gustando cada día, los programas que hablen de sexo o pornografía, programas tabús, etc. ¿Eso es sano para una sociedad que está perdiendo sus valores? Armand Mattelart manifestó "Somos los que vemos". En este caso: Somos los que escuchamos. En la interrogante: ¿Los medios de comunicación salvadoreños transmiten programas educativos?

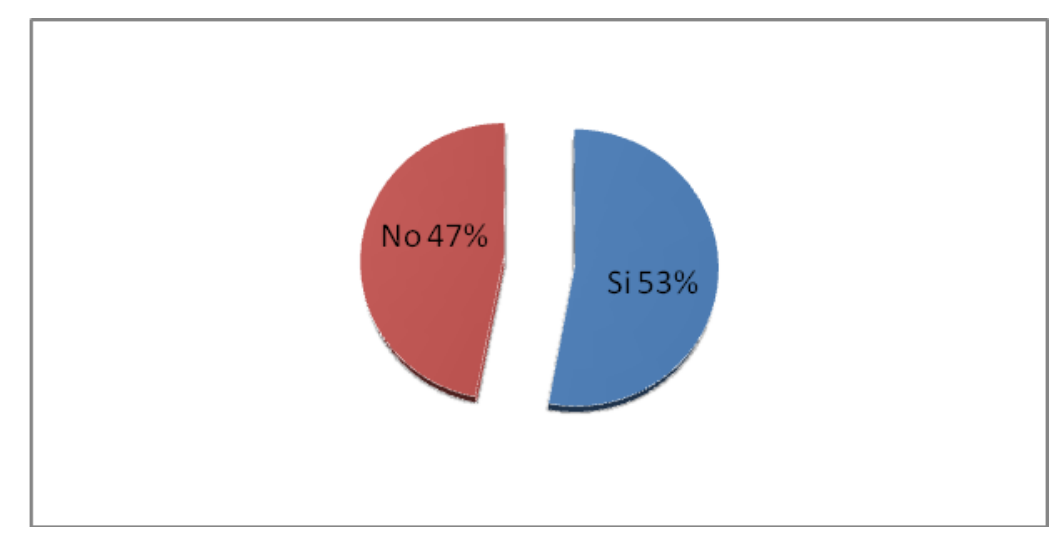

Fuente: Investigación propia

El 53\% manifestó que los medios de comunicación en el país transmiten programas culturales, mientras un $47 \%$ manifestó que no. Esto radica en que el dial y los canales de televisión se han destinado como visión empresarial en producir más programas de entretenimiento o con poco nivel cultural. Los rescatables son "Quién quiere ser Millonario", o programas copiados de otros países como "Milena tu Amiga", en donde su enfoque es invitar a personas a discutir sobre temáticas sobre homosexualismo, maltrato infantil, infidelidad, hombres participando en concursos de belleza, etc.

El programa "Quien quiere ser Millonario", son de los que más agradan al televidente, ya que sus interrogantes y formato educa hasta a los niños.

Por otra parte, los "Tolkshows", son los que en muchas ocasiones han liderado los niveles de audiencia, programas que, al final vienen a identificar falsas vidas de los artistas, de 
millonarios o de un político. Son escasos los programas culturales, en donde nos enseñen valores o cultura.

Respecto a lo de programas que en cierta medida años atrás eran tabú como, invitar a homosexuales o travestis a canales de televisión, se preguntó: ¿Para usted el Ministerio de Gobernación regula los mensajes pornográficos y violentos en los medios de comunicación?

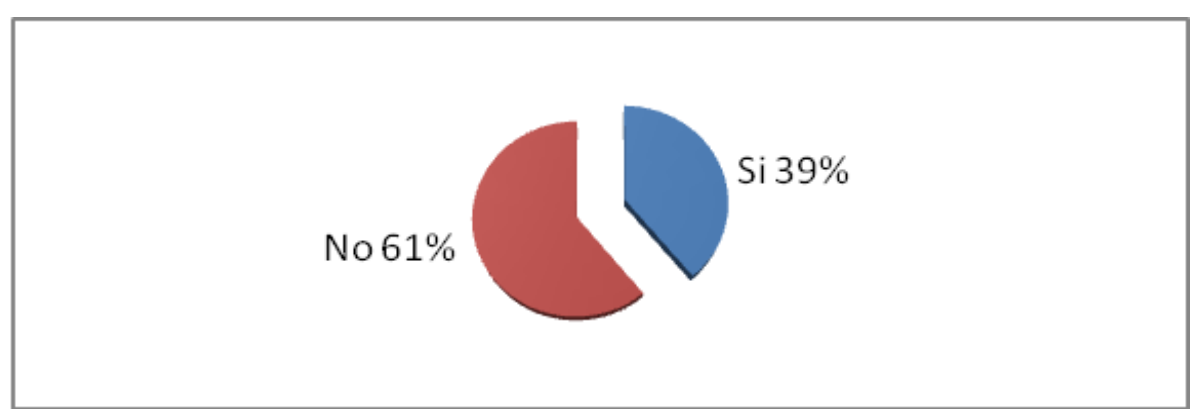

Fuente: Investigación propia

El 61\% manifestó que El Ministerio de Gobernación, no la regula, mientras un 39\% analizó que si hay regulación. El Ministerio de Gobernación, ente encargado de revisar cada programa que se transmite, tiene la potestad de multar a un medio de comunicación, empero, seguimos viendo mensajes y programas con anti valores ¿Será que su personal no está capacitado o son manipulados?

Suficiente sintonizar un programa televisivo y verificar, los mensajes subliminales y de doble sentido que envían los televidentes. Nuestra cultura latinoamericana, está cada vez más "americanizada" y copia todo lo que sea para la sociedad del consumo, lo que estimula al espectáculo barato y en otros casos, cuando hay intereses, los mensajes violentos y pornográficos no son censurados.

Mencioné que en el país se está abriendo la brecha para darle oportunidad a los homosexuales para realizar programas, cuñas o comerciales. Por ello se preguntó: ¿Está de acuerdo que en la publicidad se estén tomando como modelos a personas homosexuales? 


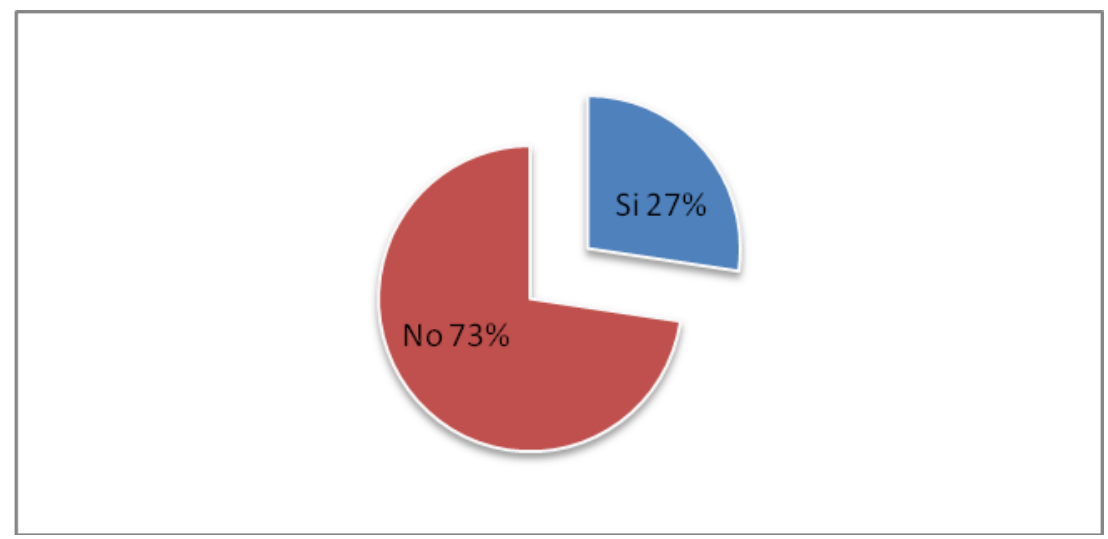

Fuente: Investigación propia

El $73 \%$ respondió que sí está de acuerdo, mientras un 27\% respondió no. Así que tenemos aún oportunidad de tener valores en este caso, aunque los Derechos Humanos, asociaciones internacionales y nacionales, están poco a poco dándonos la idea que ellos tienen sus derechos y no debemos excluirlos.

Incorporo un ejemplo, en el cual se evidencia el mensaje de doble sentido, en donde el guión dice que se debe "agarrar del palito". El mismo comercial transmitido en radio, es más latente la inclinación al campo homosexual, ya que hasta el que hace la voz en "off", hace la imitación.

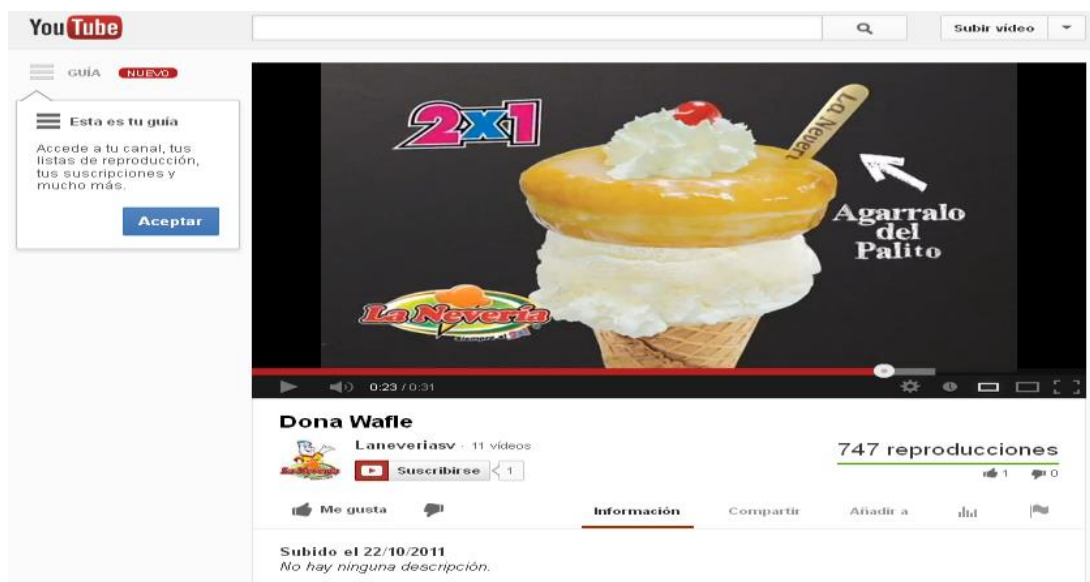

Fuente: http://www.youtube.com/watch?v=WGb8hUgZ0zc 
¿Qué tipo de programas mira en la televisión?

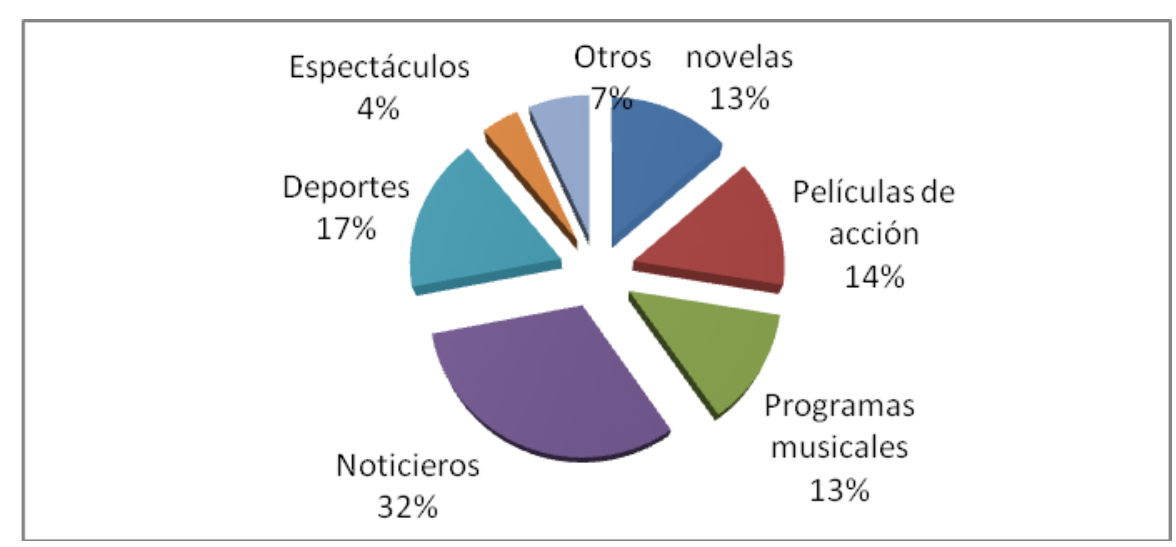

Fuente: Investigación propia

Una interrogante que cuesta contestarla, el pastel es variado en la televisión, más con las redes sociales, Youtube y tantas opciones. Quizá, por los niveles de violencia e inseguridad, las personas respondieron que miran noticias con un 32\%, 17\% deportes, $14 \%$ películas de acción, $13 \%$ novelas y programas musicales. Se comprueba que no somos tan cultos, como se evidencia en esta encuesta. El entretenimiento y programas de ocio son los primeros lugares, sin embargo es preciso analizar el ¿por qué razón prefieren noticieros?, a los jóvenes no mucho les gusta estar pendiente de muertes y asesinatos, sin embargo, nuestra cultura está cargada por esos acontecimientos.

Con respecto a los periódicos salvadoreños, deseo manifestar una anécdota cuando fui becado en el año 1994 a estudiar "Televisión Informativa" en la Universidad del País Vasco (UPV). La beca era de aprender y llevar datos referentes sobre los canales de televisión en El Salvador, los estudiantes de la UPV, deseaban conocer más sobre el canal educativo en el país "Canal 10 Televisión Nacional Educativa". Sin embargo, así como en todos los países, haciendo referencia al medio impreso, hay periódicos sensacionalistas y cargados de pornografía. En El Salvador existía "La Noticia", el cual era un periódico para presentar mujeres semidesnudas y no una información sería, o sea con formato amarillista. 
En esa ocasión, otro compañero becario de Perú Fredy Yanque, analizó periódicos amarillistas de su país, en donde los alumnos quedaron sorprendidos por las fotos de mujeres semidesnudas e historias amarillistas y con pocos espacios intelectuales.

En el año 1994, El Salvador tenía apenas dos años de haber firmado los Acuerdos de Paz, en esa época, los medios de comunicación proliferaron más y, en tiempos de la guerra, la principal misión era tener noticieros para informar.

Actualmente en El Salvador, circula a veinticinco centavos de dólar el periódico MAS, el cual adolece de editorial o artículos de reflexión, su interior está lleno de fotos de mujeres semidesnudas, un vocabulario con bajo léxico, deportes y otros menesteres. A pesar de todo, es de alto consumo. Un periódico al estilo amarillista.

Analicemos por tanto la interrogante: ¿Está de acuerdo que en el país existan periódicos como MAS para inculcar malos hábitos con respecto a su vocabulario?

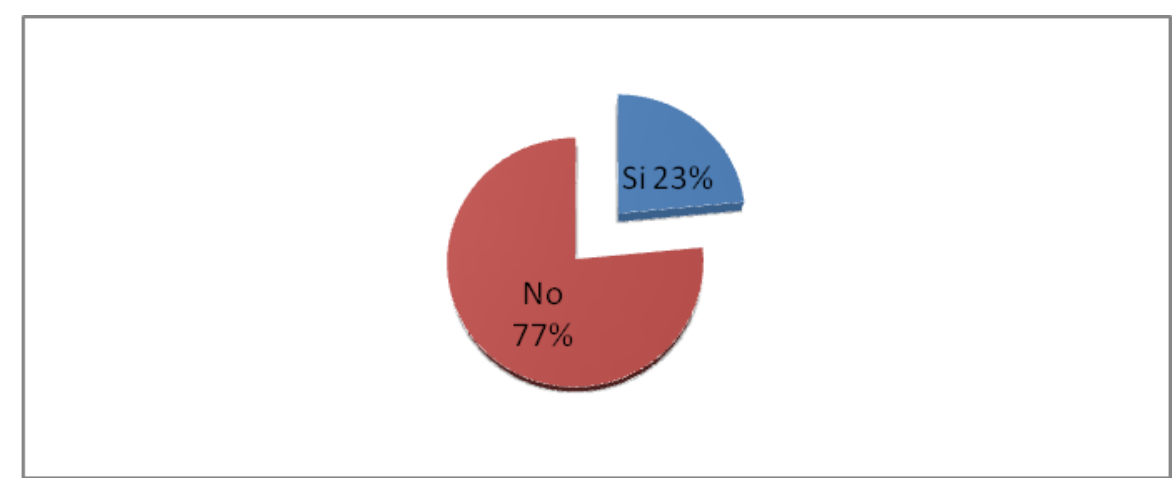

Fuente: Investigación propia

El $77 \%$ manifestó que no está de acuerdo y un $23 \%$ que sí. El vocabulario es el que lo caracteriza, el amarillismo al rojo vivo es, su anzuelo para la venta diaria.

Usted puede tener acceso a las páginas del periódico MAS, el cual adolece de formato digital. Su vocabulario, en pocos segundos evidencia hacia qué tipo de segmento poblacional está dirigido. 


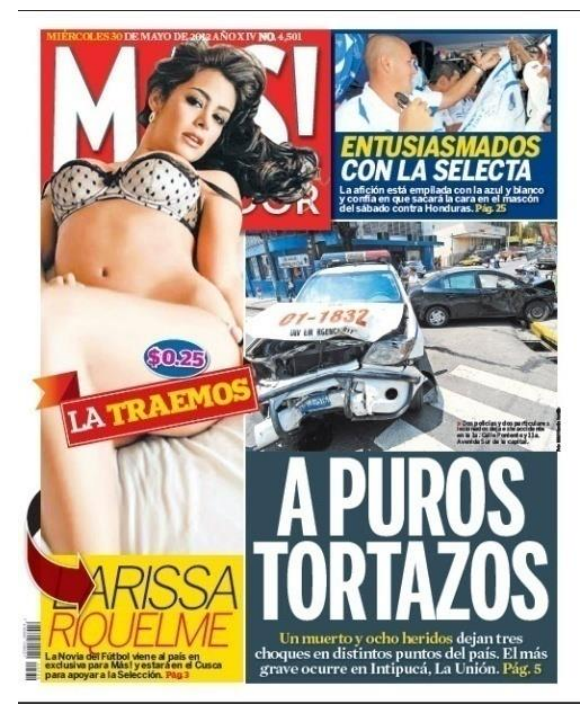

Fuente: $h$ ttp://twicsy.com/i/YDowCb

Se comprueba que en este periódico hay vocabulario que no se adapta en ningún momento, al que nos enseña la Real Academia Española, la vulgaridad y un vocabulario que es más apto para personas mal educadas ¿Están de acuerdo los padres de familia, que los niños se eduquen leyendo este tipo de periódicos? La segmentación de mercados, nos enseña que cada medio de comunicación cuenta con su segmento de seguidores.

\section{El otro inquilino: El Facebook}

Analizando al nuevo inquilino, a los nuevos infantes que rápido crecieron "las redes sociales". En este caso la red social Facebook, el cual es también parte del ocio, entretenimiento, además de perjudicar sentimientos y la falta de relaciones humanas.

Incorporo en este trabajo de investigación, una encuesta sobre las redes sociales en Costa Rica, en donde encuestaron a 600 personas. Los nuevos insights(ideas) de las redes sociales, publicado por Advertising Age. Es curioso saber que Facebook es parte del diario vivir. Veamos lo que más molesta de las redes sociales. Incorporo en orden ascendente las preferencias, a saber:

$\checkmark$ Que el jefe me quiera agregar como amigos en Facebook.

$\checkmark$ Que me manden cosas como: "quién visitó tu perfil" o "quién vio tus fotos". 
$\checkmark$ Que me manden aplicaciones o juego que me pidan "likes" o que me una a su página.

$\checkmark$ Que me etiqueten en fotos que no quería

$\checkmark$ La gente que se pasa con el Facebook en el trabajo, etc.

Mientras lo que le gusta a las personas en redes sociales están:

$\checkmark$ Encontrarse con ex compañeros de escuela y colegio

$\checkmark$ Cuando la pareja cambia su situación sentimental

$\checkmark$ Cuando alguien demuestra interés en mí

$\checkmark$ Información de interés al día en un solo medio

$\checkmark$ Hacer lo que me dé la gana, etc.

Si se aplica la encuesta anterior a otros públicos o países, las encuestas no variarían. En mi interrogante nada más me aventuré a conocer alguna preferencia: ¿Para qué utiliza las redes sociales?

$\checkmark$ Ocio $39 \%$

$\checkmark$ Buscar amistades $26 \%$

$\checkmark$ Aspectos educativos $15 \%$

$\checkmark$ Ofertas laborales $13 \%$

$\checkmark$ Marketing $7 \%$

Se comprueba que las redes sociales son otro dueño del tiempo, en especial de los jóvenes, ya que en El Salvador, son una población que tiene más acceso a las redes sociales y le interesa conectarse con el objetivo de buscar amistades y entretenerse ociosamente.

Incorporé una interrogante acerca del uso de las redes sociales, el nuevo inquilino que vino a quedarse en nuestros hogares como un parásito ¿Para qué utiliza las redes sociales? 


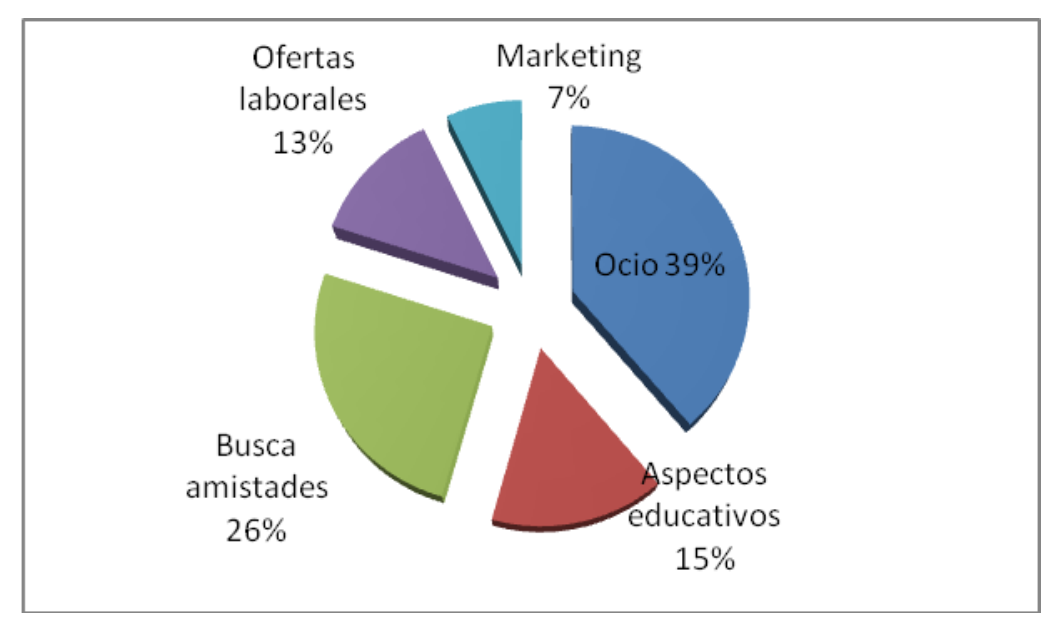

Fuente: Investigación propia

Se analiza: El $39 \%$ lo utiliza para ocio y un $26 \%$ para buscar amistades. Se comprueba que no es utilizado para aspectos educativos, el cual fue el fin principal objetivo de Mark Zuckerberg al crearlo. A este inquilino, se le suman muchos seguidores a diario, conectados para aspectos de ocio, entretenimiento y para mercadear de todo.

Las redes sociales, son, otro punto importante que analizar. Sus efectos en el cambio de la personalidad, los suicidios por supuestas infidelidades, el ocio, el "mata tiempo" de las personas que no encuentran trabajo, son puntos de partida para variadas investigaciones. En la encuesta, se refleja que Facebook, es utilizado para el consumo del ocio. Especifico que se tomó a Facebook nada más como asunto de encuesta, ya que, es la principal red social en El Salvador.

Haciendo referencia a otro segmento de la población "la niñez", me atrevo a decir que: Siempre es y será la más vulnerable hacia los medios de comunicación. La programación, especialmente la televisiva incide en su comportamiento, veamos: ¿Cree que la programación televisiva incide en el comportamiento de la niñez? 


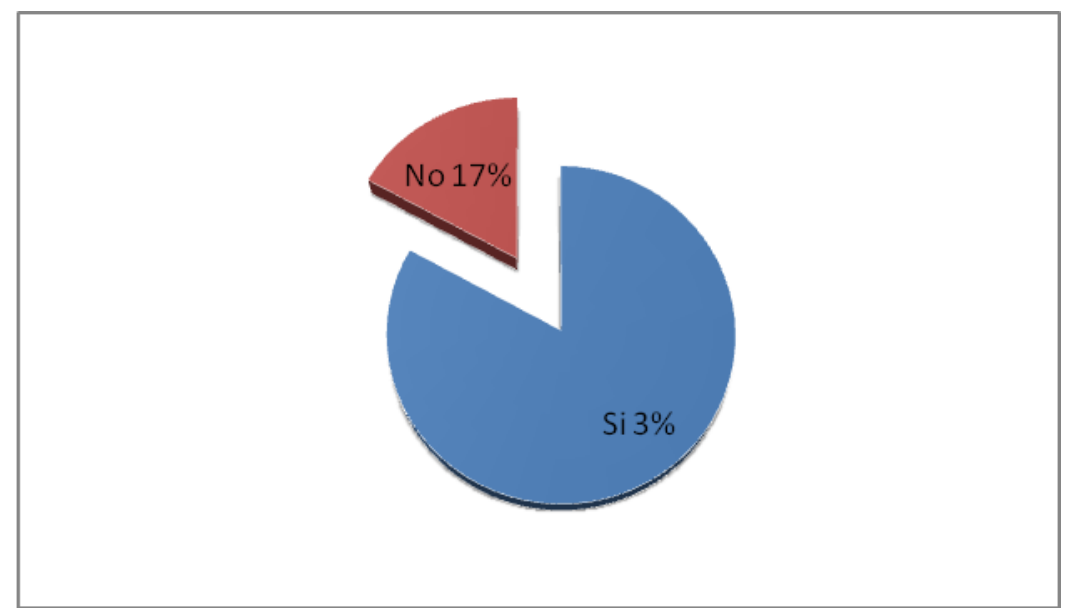

Fuente: Investigación propia

Mi tesis para graduarme de licenciado, versó sobre esta temática, en donde realizamos un experimento, a saber: Colocamos a dos niños a mirar el programa de moda en los años noventa "Los Power Rangers". Inmediatamente, los niños sentados en un sofá y, enfrente del televisor empezaron a golpearse y tirarse de patadas. Quedó esta evidencia grabada en una cámara escondida.

Cuando, defendí mi tesis para graduarme de licenciado "Incidencia de los programas pornográficos, criminales y violentos, en el comportamiento de la niñeez salvadoreña", los catedrátcos del jurado, se sorprendieron como un programa puede rápido manipular el subconciente de los seres humanos y luego actuar de forma violenta.

Los resultados arrojan que un $83 \%$ manifiesta que sí inciden en el comportamiento, mientras un $17 \%$ mencionó que no. Siempre la televisión ha sido la niñera que a pausas ha mal educado a los niños.

Sería una noticia fabulosa que encontramos evidencia sana de que los aparatos receptores "televisores" cambiaran las actitudes de los niños y hasta de los jóvenes, sin embargo, vemos la siguiente interrogante: ¿Los medios de comunicación hace cambiar los valores enseñados en el hogar y la escuela? 


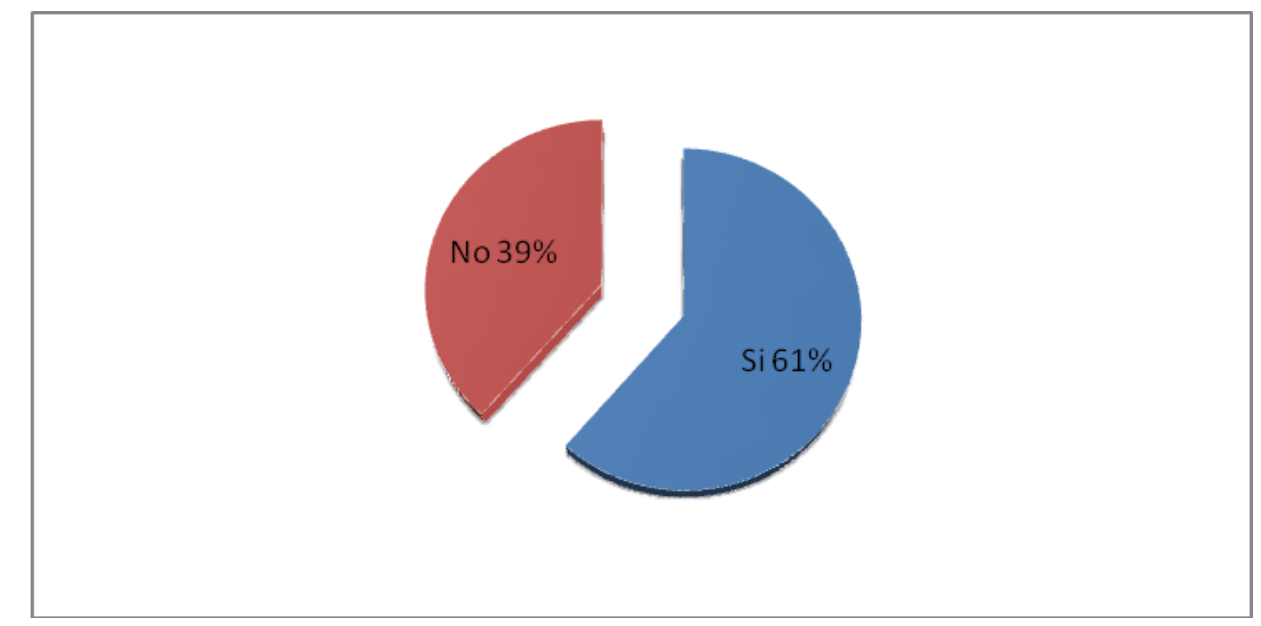

Fuente: Investigación propia

Los aspectos sociales, en especial en la cultura salvadoreña, han demostrado que los medios de comunicación son la niñera. En especial a miles de hogares en donde los niños crecieron sin sus padres de familia. Los padres de familia emigraron hacia Estados Unidos con la misión de buscar oportunidades laborales. Al final, los medios de comunicación social, son los encargados de bombardear mensajes subliminales.

Los abuelos son los encargados del cuido y crianza de los niños y jóvenes. Y, los valores son mezclados con la programación radial y televisiva. Se evidencia con solo ver los videos musicales, en donde hay hombres besándose y mujeres lesbianas manoseándose. Al final se tienen los resultados.

Una sociedad que vive y piensa como los medios de comunicación. El 61\% manifestó que los medios de comunicación siguen ganando en la incidencia en los valores. $39 \%$ de hogares recatados, que están atentos en qué miran los niños y saben lo nocivo que es la pantalla, respondió que no son los MCS los que cambian los valores. 
Para finalizar el análisis de las preguntas: ¿Por qué razón prefiere programación de cable que programación local?

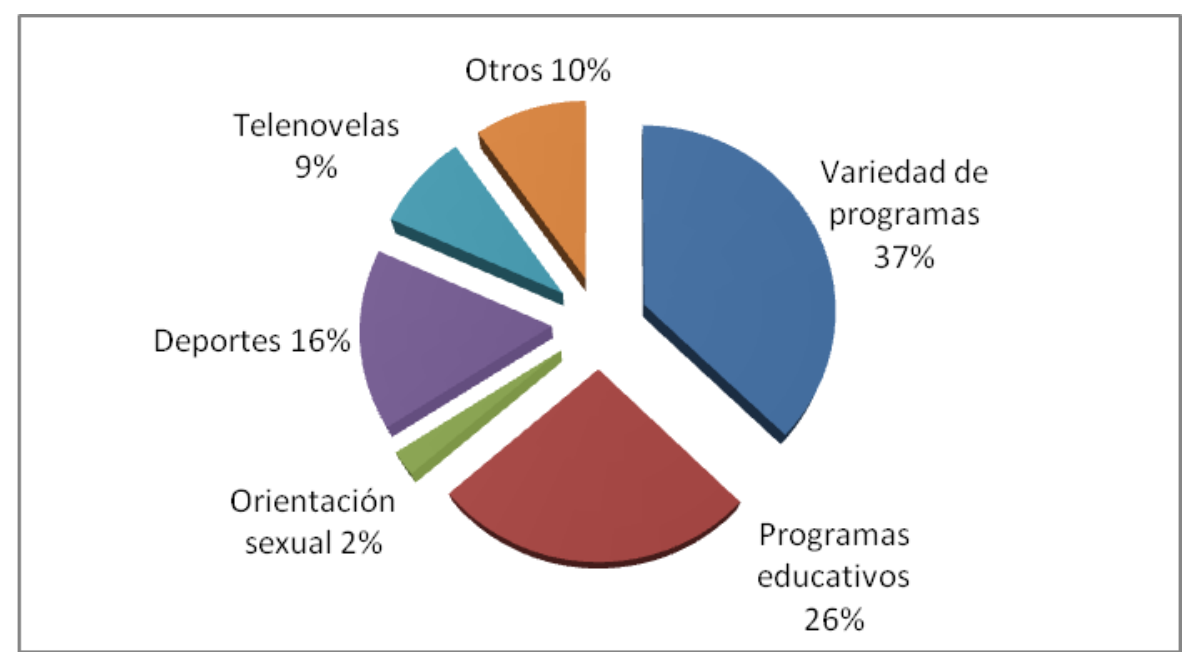

Fuente: Investigación propia

Todos, hasta en las comunidades de escasos recursos económicos, se comprueban cuando uno pasa cerca de sus casas, que tienen cable, las pequeñas antenas de las diferentes compañías hacen apuestas y, las antenas, parecen banderas encima de los techos. Quizá sea el tipo de nivel cultural el que logré identificar gustos y preferencias, a continuación los resultados:
$\checkmark$ Por la variedad de programas 37\%
$\checkmark$ Programas más educativos $26 \%$
$\checkmark$ Por los canales deportivos $16 \%$
$\checkmark$ Programas con orientación sexual 10\%
$\checkmark$ Por los canales de telenovelas 9\%
$\checkmark$ Otros 2\% 
Se evidencia, que hay problemas sociales latentes como inseguridad y violencia, sin embargo, son millones de personas que cuentan con servicio de cable. Lástima que la mayoría, lo utiliza para perder el tiempo. Esa es la cultura de masas que se alimenta de programas chatarra y nada de educativos.

\section{La televisión y sus estereotipos}

Los salvadoreños admiramos la programación con temáticas controversiales, de doble sentido, programaciones con mensajes sexuales, etc. Nos inyectan tal aguja hipodérmica, una programación que nos envuelva, nos cautiva. Los programas, nos envuelven en una "espiral del silencio".

"El contenido del estereotipo que aparece en los medios viene de la interpretación social de un grupo..." "el estereotipo llega a ser conocido por la comunidad, aunque no todos lo adopten como verdad; como tal, el estereotipo sirve como poderoso instrumento de información".

En todas partes del mundo, la televisión especialmente, es un referente en donde logra sus objetivos "persuadir", por lo tanto hay aspectos en los que los medios de comunicación nos informan sobre cuestiones que nos hacen reflexionar.

¿Todo lo que se observa en la televisión es verdad? A mis alumnos les pregunté sobre aspectos en los que los medios de comunicación están realizando spots en donde se manifiesta un apoyo a los homosexuales o en otro sentido, los medios de comunicación en especial la televisión, están ejerciendo poder para lograr tener a los homosexuales como una señal que deben ser aceptados.

La Comisión Nacional Contra el Sida, lanzó una campaña "No me etiquetes", en donde manifiesta que están estereotipando a los homosexuales para comunicarle a la audiencia que no deben ser discriminados.

Los diferentes líderes de opinión, religiones y asociaciones, no están de acuerdo en este tipo de campañas publicitarias. 


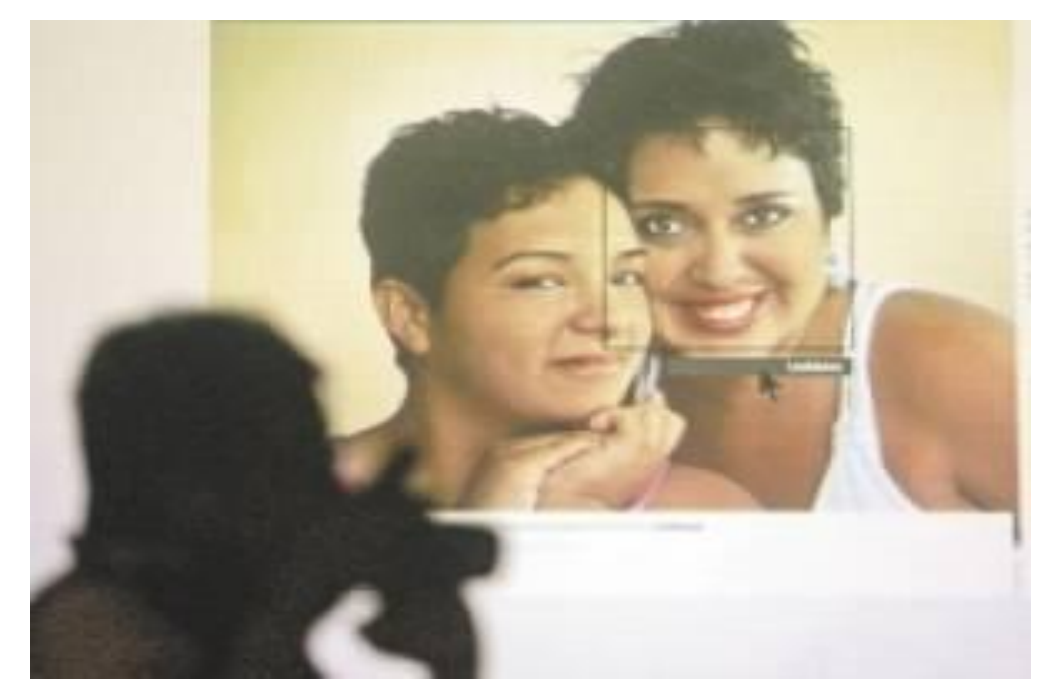

Fuente: Foto tomada por el periódico La Prensa Gráfica.

http://m.laprensagrafica.com/2011/12/16/conasida-oficializa-\%E2\%80\%9Cno-meetiquetes\%E2\%80\%9D-2/

"La Comisión Nacional Contra el Sida (CONASIDA) oficializó ayer en el país la campaña publicitaria "No me etiquetes".

Los mensajes que se transmiten en los medios de comunicación, pretenden evitar el estigma y la discriminación que sufren las personas que conforman la diversidad sexual.

Bien por la no discriminación de las personas portadoras de $\mathrm{VIH}$, pero ¿Contribuye positivamente en la salud emocional de la niñez, o es un plato muy fuerte para los infantes, a quienes puede afectarles de manera negativa en su corta edad? Se considera un tema muy importante y delicado. Se debe tratar oportunamente con la persona o autoridades idóneas.

"La idea es promover el respeto. En la primera medición del índice y discriminación del VIH se refleja que el $34 \%$ de las personas diagnosticadas con el virus han tenido al menos una manifestación de discriminación, afirmó Herbert Betancourt, de ONUSIDA."

Por lo tanto, la comunicación como tal la cumple el papel fundamental de no censurar o dejar de llenar sus bolsillos, ya no importa la campaña que tenga que realizar. La televisión con su poder visual y auditivo colabora más llegando a los hogares. Son los niños en especial los que preguntan: ¿Papá: ese es hombre o es mujer?. 
La publicidad con modelos o simulaciones de "gays" es moda en otros países, en Francia por ejemplo McDonald's, muestra a un chico homosexual y su relación con su papá mientras comen una hamburguesa. Promueve un poco la tolerancia hacia las diferencias en los seres humanos.

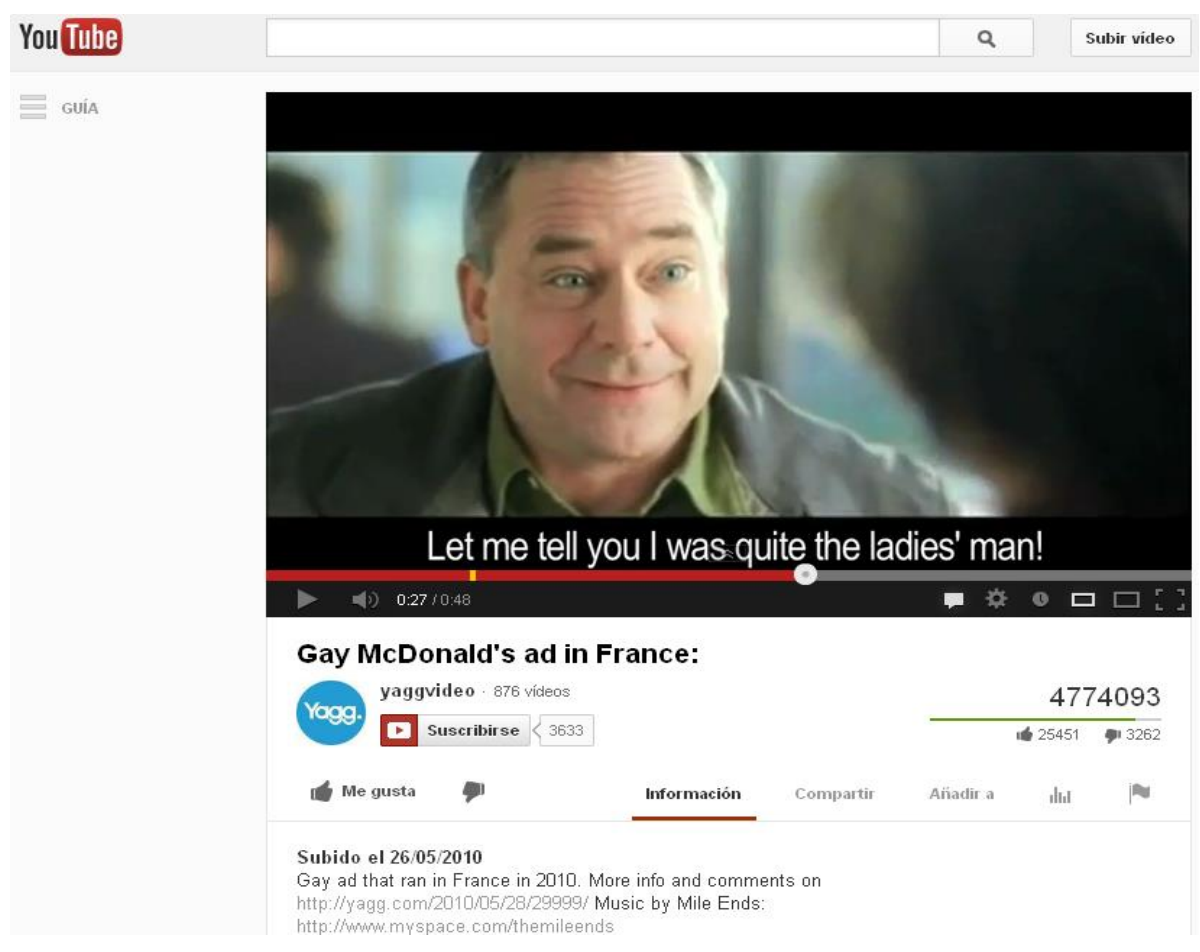

Fuente: $h t t p: / / w w w . y o u t u b e . c o m / w a t c h ? v=S B u K u A 9 n H s w \& f e a t u r e=p l a y e r \_e m b e d d e d$

En el comercial de IKEA en Austria, muestra claramente a dos jóvenes que se tocan y hacen simulaciones homosexuales. ¿Permitirán en El Salvador y otros países latinoamericanos, la publicidad en donde se aceptan a los gays?

Los estereotipos en países latinoamericanos están repletos de mensajes, programas, y consumismo norteamericano. En El Salvador, la población es consumista y tiende a imitar todo lo que observa en los MCS.

Los MCS, siempre han estereotipado a las mujeres como imagen sexual, ahora está entrando la moda en el país de identificar a homosexuales que son tomados como modelos en los anuncios de televisión, cuñas radiales, periódicos, MUPIS, entre otros. ¿Está de 
acuerdo que en la cultura latinoamericana se permita este tipo de transculturizaciones? ¿Tiene que respetarse la igualdad de géneros?

\section{Los medios de comunicación como fuente de poder}

No pueden vivir los medios de comunicación sin la publicidad, así como los seres humanos no podemos vivir sin aire, hasta la radioemisora más arcaica o con bajos recursos tiene que tener un anunciante, excepto si tiene filántropos que la mantienen, o es una Universidad o asociación. Empero, en la vida nada es gratis. Hasta los medios de comunicación religiosos tienen publicidad.

En el país, la publicidad es parte de la vida diaria, no estamos exentos en ingerir una centena de comerciales al día, el tráfico en las calles hace que los oyentes consuman más radio y es en donde les bombardean con publicidad.

Los medios de comunicación sobreviven gracias al poder de la publicidad, por lo tanto, tienen que entretener y buscar la manera de mantener la atención a sus dependientes o zombis.

En el caso salvadoreño, también, los medios de comunicación son manipulados por los que tienen el poder en sus manos, ejemplo es el caso del expresidente Antonio Saca, quien es propietario de muchas radios en El Salvador y Centroamérica y, logra llegar a los radioescuchas con el mensaje propagandístico "Reflexiones". Así en Europa, en América del Sur, los mandatarios han logrado ganar elecciones a través de mensajes bien elaborados a través del consumo radial. Caso el presidente Hugo Chávez en Venezuela.

"De hecho, es Saca quien narra las historietas edificantes, cuyo contenido o mensaje pretende ser (1) un baño de memoria y entusiasmo; (2) una fuerza que hinche el corazón de renovado patriotismo, a la vez que envilezca las escuálidas artes reflexivas de ciertos salvadoreños; (3) un profundo despertar del amor propio. Pero lo más importante, (4) una amable invitación a amar a El Salvador tal cual es: con la atroz realidad de sus muertos; el tinglado de la burocracia estatal, con sus corrupciones e ineficiencias; con lo más sórdido de su clase política, de la que forma parte el mismo Saca; en fin, un Estado-Nación abatido por el narcotráfico, las pandillas y los rufianes de cuello blanco. Pero todo eso no importa. Debemos amar su gente, semillero de honrados, trabajadores, luchadores y, por supuesto, 
"malacates", como diría el mismo expresidente. A todos ellos hay que prodigarles amor y rendirles pleitesía".

En el presente mandato presidencial (2009-2014), liderado por Mauricio Funes, se creó el programa "Conversando con el Presidente", el cual es una copia el programa del presidente venezolano Hugo Chávez. Los medios de comunicación, deben servir para culturizar y educar y, no ser fuente de poder o manipulación de masas. Para aclarar bien como se utiliza el poder, el presidente Funes, aprendió ese oficio, ya que trabajó más de veinte años como presentador de programas de opinión en canales locales. Esto se evidencia en países desarrollados, en donde los mismos presidentes como Silvio Berlusconi son propietarios de cadenas televisivas.

Por lo tanto, un buen uso de los medios de comunicación implica:

$\checkmark$ Servir a los receptores como fuente de información.

$\checkmark$ Buscar cambiar el pensamiento, sin abrir heridas como el pasado conflicto armado.

$\checkmark$ Crear programas culturales, los cuales ayudarán a formar pensadores.

$\checkmark$ Realizar "Teleclases", así como los transmitía la Televisión Educativa Salvadoreña, canales 8 y 10 . Actualmente solo es el Canal 10.

$\checkmark$ No aprovecharse del poder mediático para engañar con consumismo y propaganda negra.

$\checkmark$ Formar valores y la convivencia ciudadana.

$\checkmark$ Educar con más programas religiosos y llenos de valores espirituales.

\section{Los medios de comunicación inciden en el consumismo}

¿Pueden las personas vivir sin medios de comunicación? ¿Podremos controlar nuestros impulsos para dejar a un lado el control remoto? Con dos millones y medio de salvadoreños en el extranjero, en especial en los Estados Unidos, sabemos bien que nada más nos separa la distancia. Queremos vestir, comer, hablar y tener una vida al estilo americano, tan solo 
basta que nos envíen la ansiada remesa familiar y "a comprar modas estadounidense se ha dicho".

La publicidad y el consumismo que impera en el país, hace que las personas estén envueltas en una bola de cristal falsa, en donde los clientes, compran todos los productos y servicios que les enseñan a través de los medios de comunicación.

Los teóricos de la comunicación han de estar diciendo en sus tumbas que tenían razón, ya que, siempre analizaron al ser humano como consumista, al cual los medios de comunicación envuelven con una mentira y lo hacen caer en la atentación del consumismo. El famoso teléfono BlackBerry es un ejemplo de consumismo, en donde miles de jóvenes son parte de la estrategia publicitaria. En El Salvador, el "BB", como es conocido, es el teléfono más usado por la juventud, mercadológicamente se supo posicionar.

En la sociología y psicología de la comunicación, se han realizado estudio de audiencias, de consumos culturales, consumos mediáticos, comportamientos de los individuos hacia los medios de comunicación, la manipulación de masas, etc.

El 25 de noviembre del 2011 El Salvador, en el país, se experimentó un ensayo de un típico estereotipo estadounidense, de masificación de medios, de transculturización, ya que miles de personas se volcaron a comprar en un almacén de electrodomésticos. Hubo un portón que casi la derriban, personas golpeadas e inconformidades, todo por querer comprar productos ofertados.

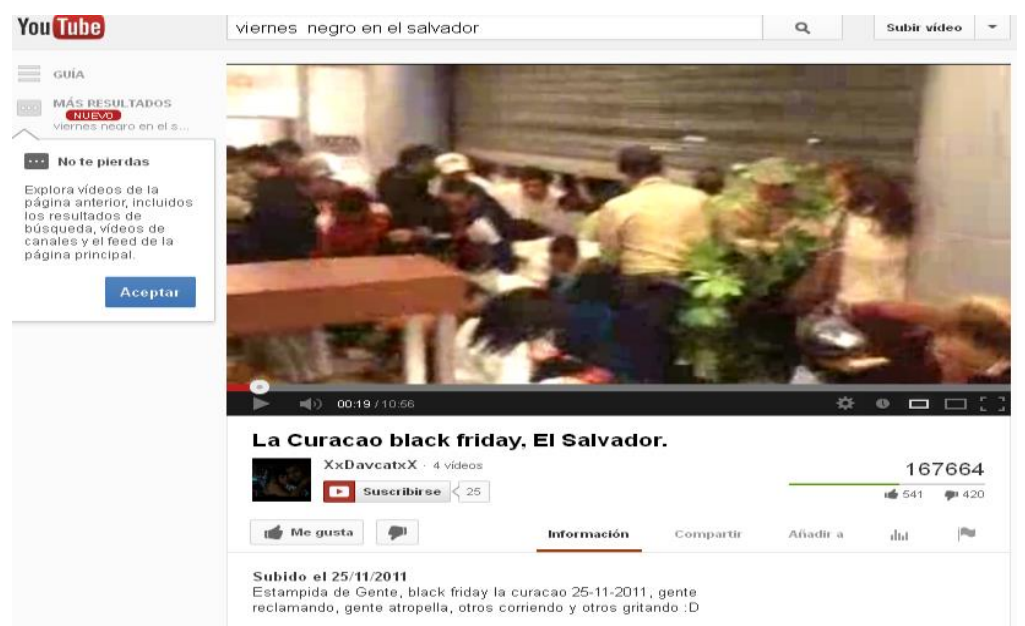

Fuente: $h t t p: / / w w w . y o u t u b e . c o m / w a t c h ? v=A i F X S I 8 O n U 0$ 
Mientras en Estados Unidos en el año 2011, moría una persona y una señora hasta rociaba gas pimienta a muchos por querer entrar primero al almacén, en este país quisieron copiar lo mismo. El famoso "Black Friday" se consumió en el país como lo esperado.

Así actúa el consumismo, los catedráticos en el área de comunicaciones sabemos bien cómo actúan y masifican a las sociedades y como hacerlas que queden hipnotizadas por la programación, en especial la televisión.

Una actividad de relaciones públicas envuelta en una nota aclaratoria se difundió el siguiente día, en donde el almacén se disculpaba con los clientes por los incidentes. Mientras tanto, las redes sociales como Facebook ya habían difundido un video de diez minutos en donde se verificó que el "Viernes Negro" cumplió la profecía de decirles a miles de consumidores "vengan a consumir".

Jesús Martín Barbero en su libro Mediación y Mediaciones envuelve este tipo de actitudes que hacen al ser humano una fuente de consumismo.

Y, para variar, como lo mencioné en este mismo escrito, somos un país consumista, eso gracias a la masificación de los medios de comunicación.

"El Salvador ocupa el deshonroso tercer lugar de mayor consumo en el mundo. En enero de 2011, de acuerdo al informe de Naciones Unidas por "cada 100 dólares producidos se consumen 102,4 dólares". "El Salvador invierte poco y ahorra aún menos: en 2008 y 2009, la inversión promedió el 14\% del PIB (producto interno bruto) y el ahorro el 9,3\%", añade el documento, e indica que "en contraste, los países de alto crecimiento económico presentan tasas de ahorro e inversión del $25 \%$ o más con relación al PIB". En el mismo sentido se señala que "El Salvador es uno de los cuatro países de América Latina que más ha perdido productividad en relación a EE.UU. "El Salvador ha tenido un crecimiento de 1,1\% desde 1960. Se necesitarían 29 años para alcanzar el nivel de desarrollo de Costa Rica y 47 años para alcanzar el nivel de desarrollo de Chile..."

Como mencioné anteriormente, con los tres mil quinientos millones de dólares anuales, que mandan los "hermanos lejanos", El Salvador, sería uno de los países más educados en la región. Empero, la mayoría de personas que recibe ese dinero, lo ocupa para gastos varios 
como: artículos de primera necesidad, ropa, calzado, paseos. A la educación no le ponen mucha atención.

Los mass media, inciden en el consumismo, eso se refleja en los días feriados, en el día de las madres, día de los enamorados, Navidad, etc. ¿Cómo podemos hacer para que los medios de comunicación eduquen mejor a un consumismo de la educación? ¿Por qué razón no hay campañas mediáticas para que cambiemos a través de la educación?

\section{Entre una programación de entretenimiento versus programación cultural}

El Canal 10 Televisión Cultural Educativa, es un canal del gobierno de El Salvador, el cual transmite "entre comillas" programas eminentemente culturales en temas importantes de historia o actuales, que dejan información cultural al televidente. Su rating, es bajo, no despierta el interés de los televidentes, excepto aquel intelectual deseoso de consumir programas educativos, en donde se transmitan programas de poesía, literatura, teatro, noticieros sin violencia, entre otros aspectos.

Mientras tanto, los canales comerciales transmiten programas enlatados y remakes de telenovelas al estilo narco. Eso le gusta al televidente. A las clases dominadas les gusta ver programación de entretenimiento, aquella que no tiene contenido, la que sea más fácil de digerir o consumir. Seguimos siendo una masa que rápido se llena de otras culturas.

La capital mexicana, por ejemplo, la mayoría de población nunca ha visitado un teatro y, los demás se la pasan viendo novelas, el cual es el parte de la vida del típico mexicano. Eso lo aprendí de un taller sobre "Televisión pública" en un hotel capitalino. Se evidencia, también el bajo grado cultural.

¿Cuántos programas culturales se transmiten en El Salvador? Son pocos y contados con los dedos de la mano. Así es como en la programación que se transmite a través de cable, existen canales educativos, sin embargo, las personas prefieren telenovelas, programas de chambres, reality shows, etc. 
La programación cultural es escasa, solamente las personas que están en la perspectiva de aprender, los buscan. En las radioemisoras como: Radio Nacional, existe el programa "Cuéntame un Cuento", en Radio Clásica y Radio Mundo la música es instrumental y por ende clásica. Para los niños está Radio UPA, con un formato orientado a los niños, aunque en ocasiones el tipo de música se adapta más a la juventud. Es difícil, ya que el fenómeno cultural de la música, ha llegado al extremo que, en las escuelas públicas y algunos colegios privados, las maestras enseñan en sus actos estudiantes a los alumnos con música reguetonera.

Otro caso y efecto positivo cultural, son las radios religiosas como las radios católicas Radio Ágape o Radio María. Radios evangélicas como: Radio Bautista, Radio Restauración, etc.

Lo religioso al final se convierte en una actividad cultural, un valor religioso que educa a los seres humanos, más en una sociedad convulsionada entre violencia e inseguridad en la zona centroamericana, en especial en El Salvador. Un aspecto positivo que se evidencia es que, a través de las radios cristianas, buscan cambiar en hábitos de perversión, en hábitos religiosos y con valores a los oyentes y televidentes. Ese es un punto a favor en estos medios de comunicación.

\section{Un cambio de giro a la televisión cultural de El Salvador.}

Las teleclases, las cuales nos hacían aprender a miles de personas desaparecieron, una programación que era aceptada por el Ministerio de Educación. Y transmitido en canales 8 y 10 Televisión Cultural Educativa. Los mejores maestros, eran contratados para dirigir las teleclases.

Un giro completo a lo que en realidad debe ser un canal cultural y educativo, según entrevista realizada por el periódico virtual El Faro, se analiza el trabajo que antes realizaban.

"Según César Meléndez, con el proyecto de las "Tele clases" se educó alrededor de dos millones de salvadoreños, "las personas que hoy tienen entre cuarenta y cincuenta años se educaron con las Teleclases", asegura. Cada "tele clase" contaba con su propio equipo de producción, de cinco a seis personas entre guionista, director, profesor, evaluador... Hasta ese momento la labor del canal era puramente educativa". [2] 
"Canal 10 es el canal con mayor producción propia en el país, entre 12 y 15 programas. Y su programación internacional es muy variada... ¿A qué se debe entonces el bajo índice de audiencias? Sermeño lo explica a partir de gustos e intereses. "El problema no es tanto la calidad del programa sino más bien que no estamos educados para ver y percibir cultura, al salvadoreño si no le interesa o no le gusta... no lo va a ver".

En la actualidad la programación cambió y no por criticar o hacer firmeza que no es la preferida. El canal del gobierno no llena las expectativas.

La televisión como crecimos en la década de los años 70, ya no trae lo mismo, con referencia a actos de violencia, culturales o de entretenimiento. Acá no podemos manifestar la frase "los tiempos cambian" ya que lo que ha cambiado es la tecnología, sin embargo la programación es la que siempre ha estado en constante cambio, la cual se acopla a los tiempos y cambios de políticas, leyes y aspectos antropólogos, sociales y psicológicos.

Es decir, que en las universidades no podemos estar solamente enseñando que la televisión es una fuente de emisor que nos envía un mensaje. Ahora, la televisión es interactiva y desde su matrimonio con la computadora personal, se ha hecho irreversible tomarla como se llamó al principio "La Cajita Mágica".

En el país estamos americanizados y latinoamericanizados, los programas son de corte novelesco y películas que son muy diferentes a las de antes. Antes las mujeres eran tomadas como ejemplo de pureza y fervor religioso, actualmente, las telenovelas muestran que primero, las parejas tienen que probar si el matrimonio es viable, luego se casan. Las teleseries, El Capo, Sin Senos no hay Paraíso, son programas preferidos. Les gusta la violencia y los actos sexuales en la televisión.

La mayoría de programación elaborada en el país es más de entretenimiento. Programas como Tal Para Cual, en donde nos quieren dar "atol con el dedo". En donde pasamos horas viendo nada, con guiones hechos nada más para perder el tiempo y olvidarnos de la vida real ¿Cumplen las expectativas los medios de comunicación en El Salvador? Al principio era otra visión.

Los países desarrollados como Alemania invierten bastante dinero en la programación cultural, y no se está hablando por aspectos de tamaño o educación, ya que hay otros países 
que ocupaban a los medios de comunicación, en especial la televisión como entes educadores.

\section{Las redes sociales y su posición educadora y la trasposición hacia los medios de comunicación}

Las redes sociales nos están haciendo despertar y dormirnos todos los días con ellas. Ya no es normal ver a las personas sin un teléfono BlackBerry enviando mensajes. Todo el mundo está siguiendo y haciendo noticias con las redes sociales. Cuando en una de mis cátedras, se expuso el video "Epic", en donde muestra a los seres humanos como fuente de noticias y parte de la noticia, se analizó que los medios de comunicación serán manipulados por los seres humanos, entonces ¿Quién vigilará el contenido de los mensajes? Todo el mundo publica tonterías en las redes sociales e Internet y, nadie está vigilando.

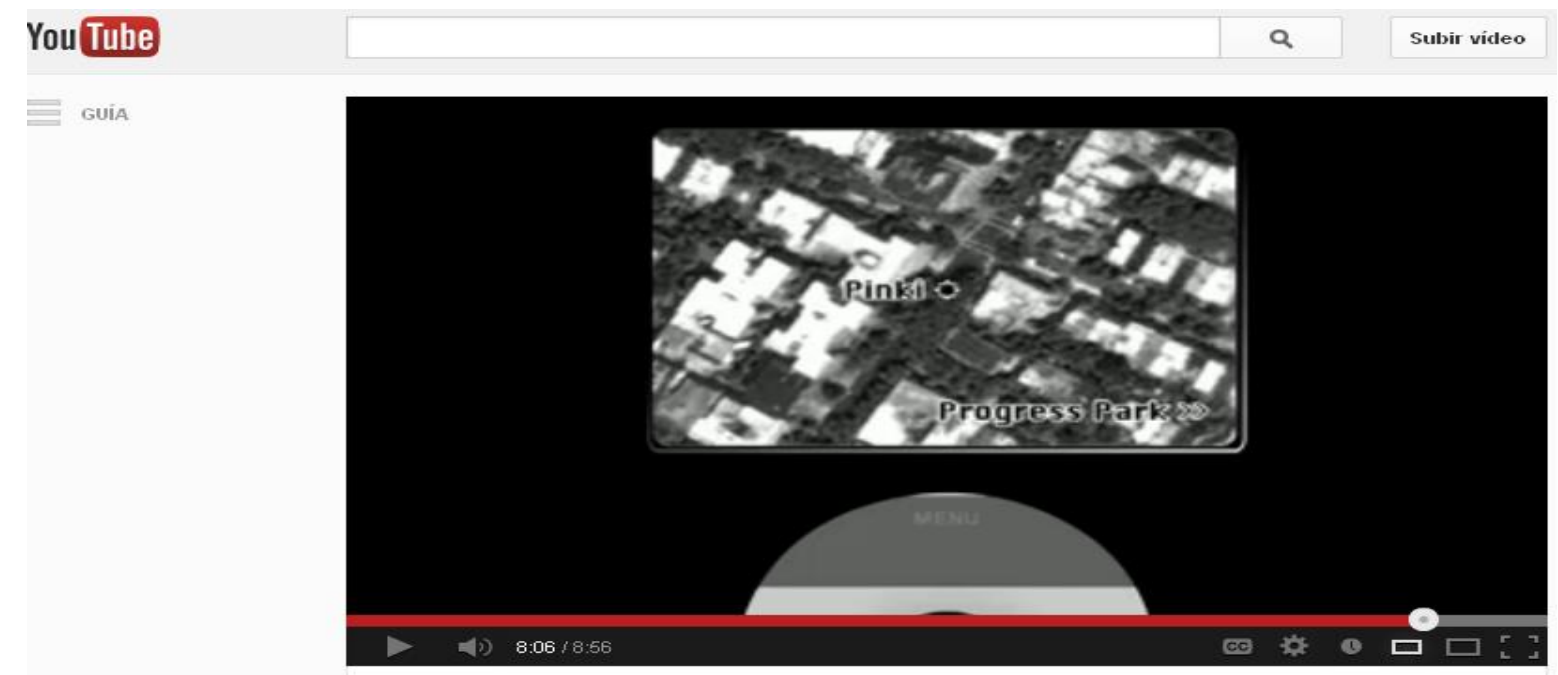

EPIC 2015 El Cuarto Poder ha decaído, Internet Año 2015

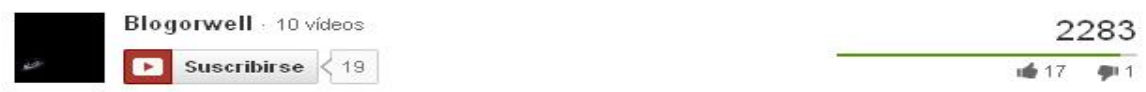

Fuente: http://www.youtube.com/watch?v=KJXvp7SfBMo

Tanto la Internet como las redes sociales son las que están siempre en nuestros hogares, ya sea en diferentes aparatos tecnológicos. Los seres humanos estamos siendo educados 
consiente o inconscientemente por la Internet; ya que, en todas las diligencias o actividades diarias están presentes. Si es para educar e investigar, excelente, pero, si es para buscar pornografía, estupideces y ocio, está mal utilizada.

Por ello, debemos ser, tanto la escuela y los padres de familia, los vigilantes a que nuestros hijos y prójimo utilicen debidamente las tecnologías de la información. No queremos que los medios de comunicación o videojuegos sean causantes de tragedias, tal es el caso de la masacre suscitada en Newtown, Estados Unidos en donde murieron 26 personas, o el tiroteo en un cine en la última película de Batman. ¿Son los malos hábitos de usar videojuegos los causantes de esas masacres en Estados Unidos?

"La preocupación sobre los juegos y la violencia es mucho más antigua que los videojuegos. Desde épocas prehistóricas, los niños (particularmente los varones) juegan a actividades violentas, como la caza y la guerra. Los animales también juegan a pelear, con la diferencia de que sus cuerpos incorporan armas mortales: fuertes quijadas, dientes y garras afiladas. Si bien es posible que cachorros de leones se lastimen mientras juegan, no es frecuente que se provoquen heridas graves. Los animales, ya desde pequeños, pueden distinguir claramente el juego de una pelea verdadera".

Entonces ¿Los medios de comunicación educan o hacen una sociedad sin valores? Cada quien se haga su juicio. Lo que es palpable es la transposición de los medios de comunicación hacia la sociedad. Recordemos que en América Latina, aun se conservan en cierto grado los valores, los cuales vienen de las buenas familias que mezclan la educación con lo enseñado en el hogar. No debemos de dejar que los Medios de Comunicación Social, eduquen y cambien la personalidad de las nuevas generaciones.

Los efectos al ver o consumir tanta televisión ya los conocemos, o mejor, menciono algunos de ellos: Niñas adolescentes embarazadas, alcoholismo, violencia familiar, irrespeto hacia los padres de familia, pensamientos individualistas, etc.

Desde tiempos remotos, los medios de comunicación han sido el principal medio para que las masas sean parte de la ideologización, el mismo Adolfo Hitler los ocupó para su campaña proselitista, realizado hasta películas para incorporar mensajes propagandísticos a los alemanes. 
En la actualidad, los mensajes de los medios de comunicación están sirviendo para analizar aspectos tanto psicológicos, culturales, antropológicos, sociales y sobre todo familiares.

Se han escrito muchos aspectos sobre este aparato, pero en esta ocasión, en el caso salvadoreño, es indispensable tomarlo en cuenta para realizar una investigación, no compleja ni con tantos datos estadísticos, sino una investigación que haga reflexionar en especial a los padres de familia, a los centros escolares, para que ejerzan un grado de concientización sobre este aparato, al Gobierno para que planifique mejor su itinerario en controlar los programas de TV.

\section{2. ¿Qué miramos en la televisión?}

El ocio más en vacaciones hace que esas horas aumenten más, ya hemos de pensar las horas extras que miran televisión los niños en las vacaciones, en especial al terminar el año escolar.

Ya sabemos que la televisión es la niñera de nuestros hijos, sabemos que les inyectan información, les moldea personalidad y hasta la forma de hablar. Por eso, prohibieron en Alemania "Teletubbies", ya que analizaron que a los niños los hacia un poco tontos por su lenguaje.

"La defensora del menor de Polonia, Ewa Sowinska, ha pedido a un grupo de psicólogos que analicen si la famosa serie televisiva para niños los "Teletubbies" tienen algún indicio de homosexualidad.

El personaje de Tinky Winky es el causante de que Sowinska considere que la serie pueda dar propaganda homosexual'. "Me di cuenta de que Tinky Winky llevaba un bolso, pero no sabía que fuera un chico", declaró Sowinska. "Más tarde supe que ahí podría haber un nexo homosexual oculto".

En la red social Facebook, realicé la siguiente interrogante ¿Qué programas miran en la televisión salvadoreña o en cable? Tomo las respuestas, tal como las publicaron. Las respuestas fueron las siguientes: son: "El Precio De la Historia, Cake Boss, Bar Rescue, Mil maneras de morir, TNT o HBO, Discovery Chanel "Mentes Criminales", El Precio de la Historia, Discovery Channel, National Geografic, ESPN, Calle Siete, En cable MONK, FRIENDS, Cheaters. En TV nacional Quien quiere ser Millonario, Caso Cerrado, Noticias en 
el 6, 12, 4. Y a veces los programas d la mañana como Hola El Salvador, quien quiere ser millonario...me parece muy educativo iii, Solo los Noticieros de Canal 12 y Canal 21, en la tele salvadoreña no hay programas buenos, Canales Locales : Telenoticias 21, Cable: El precio de la Historia(History), Discovery Kids Latinoamérica (por mi beba) y Discory Channels, En Cable Veo Discovery Chanel Mentes Criminales. Televisión Nacional Veo Grandiosas y Noticias 4vision, Mayormente cable, Food Channel, CNN International, En cable el Precio de la Historia, La humanidad, La ley y el Orden, Top Gear, Los Restauradores, Kitchen Nightmares, Yo miro una que se llama Separados en el canal 22 (Televisión Nacional de Chile), Noticieros Canal 21 y 19, 3".

Se comprueba en pocas encuestas, que prefieren televisión por cable, sin embargo, los noticieros son parte de la cotidianeidad del televidente. $Y$, con respecto a la escritura, se comprueba que hay otro tema de investigación con respecto a las redes sociales, la escritura y ortografía.

Noam Chomski, manifiesta que los medios de comunicación, hacen que las personas sean esclavas y además se dejan llevar por todo lo que les muestran. Más si son niños los que están hipnotizándose.

Con control remoto en mano, y con los televisores manipulados, se puede pasar todo el día sentados en el sofá viendo televisión. Al salvadoreño le gusta los deportes, en especial el fútbol español, se pelea y discute por El Barcelona o por el Real Madrid, le gusta mirar los programas de cable. A lo anterior se le denomina transculturización. Y, cuando se le antoja mirar televisión nacional, se la pasa mirando novelas, los famosos programas Domingo para Todos y Tal para Cual ¿Calidad o basura de programas? Cada quien que lo discuta.

En el programa Domingo para Todos, nos presenta el típico programa en donde a las personas se les toma como burlas, concursos ridículos y sin ningún contexto cultural. Mientras en otros países como Japón, los programas son educativos. Nos muestra la idiosincrasia del típico salvadoreño, concursos que no hacen pensar al participante y concursos sin sentido.

Programas como este podrá verse en otros países, pero, según mi análisis, hasta por este tipo de programas se mide la cultura y educación de un país. 
En la red social Facebook realicé la siguiente interrogante ¿Qué piensan del programa Domingo para Todos o Tal para Cual? Estos fueron los resultados:

$\checkmark$ Pues para mí ni deberían mostrarlos al aire porque lo único que hacen es mostrar el grado de ignorancia de las personas y ver como se humillan por unos cuántos dólares.

$\checkmark$ Nada que pueda sorprender algo simple y sin gracia, opinión muy personal.

$\checkmark$ No los veo porque no poseen nada productivo, menos proyectan integridad y no abonan a la cultura.

$\checkmark$ Ninguno de los dos sirve.

$\checkmark$ Existe una carencia o falta de oportunidad de creativos y buenos productores televisivos.

$\checkmark$ No hay creatividad, la misma copia de programas mexicanos.

$\checkmark$ Una mal copia de programas mexicanos y opino igual una perdida de tiempo verlos aquí en el país, deberían poner más programas familiares, que vulgares, principalmente con los conductores El Gordo Max, La Tenchis, que son lo peor de lo peor de la vulgaridad y mala educación.

$\checkmark$ Por programas como esos, es que no evoluciona la TV en nuestro país, no aportan nada más que una burla, no deja ningún mensaje positivo.

$\checkmark$ El programa Domingo para Todos perdió el enfoque de programa de entretenimiento familiar.

$\checkmark$ Deberían de hacer programas productivos, creo que, su imagen viene abajo empezando por el conductor por vulgar y sus modelos dejan mucho que desear, si lo estructurarían de nuevo y con nuevos animadores tal vez progresaría.

$\checkmark$ Muy cierto estos programas son muy malos y vulgares, el problema es que los canales nacionales están llenos de programas para adultos, y no familiares, menos para niños.

$\checkmark$ La verdad son programas que deberían ser cancelados por el Ministerio de Educación, son dos programas muy sucios en mi opinión.

$\checkmark$ Es un programa bofo que refleja una mal llamada "cultura" sin educación, nada edificante y no requiere ni una neurona del cerebro para entenderlo y descifrar las ridiculeces que se presentan.

$\checkmark$ Son un total desperdicio del espacio televisivo en la televisión salvadoreña, no tienen nada de edificante ni rescatable.

$\checkmark$ Domingo para Todos, es más rescatable que Tal para Cual. En Domingo para Todos, se podría decir que, les dan la oportunidad a las personas para ganarse unos cuantos 
billetes, pero, con Tal para Cual es caso perdido, vulgar, incoherente, salen con unas sus ideas un poco inmaduras y para ser programa familiar deja mucho que desear.

$\checkmark$ En mi opinión su "humor" llega hasta el extremo de ser ridículos. Creo que deberían suspenderlos.

Como se expresa en inglés "The show must go on", el show debe continuar, pero la programación continúa sin cambiar.

\section{Aspectos positivos de los medios de comunicación salvadoreños}

Sería injusto que al enseñar a los alumnos sobre los objetivos que tienen los medios de comunicación de educar, entretener, informar, culturizar, se diserte solo de aspectos negativos.

El amarillismo, noticias subliminales, programas con doble sentido moral, entre otros, llenan las preferencias de las audiencias, lectores y radioescuchas. Sin embargo hay aspectos positivos en los medios de comunicación salvadoreños que ayudan a culturizar.

Salvador Alas "La Choly" y su equipo de trabajo, ayudó a una campaña mediática para buscar firmas de personas que estuviesen en contra del aumento de sueldo de los diputados. Radio Scan es el medio de comunicación en donde él (La Chloly) y sus compañeros de programa colaboran con la ciudadanía a formar opinión, a que los ciudadanos se manifiesten. Manifestaciones que son diferentes a las que una radio de tendencia izquierdista mandaría mensajes para apoyo.

Otro ejemplo es la campaña de Telecorporación Salvadoreña (TCS), la cual es la cadena televisiva más grande de El Salvador, con el programa "Cosas Buenas", realiza reportajes que reflejan aspectos humanísticos que realizan instituciones o personas en bien de la sociedad. Programa que en cierta medida brinda reputación a los canales que están en mencionada cadena televisiva.

En otro análisis, hay que realizar responsabilidad social empresarial para tapar las malas expresiones y programas basura. Hay que disfrazar entre cadenas de colaboración entre los televidentes y radioescuchas para poder engañar. Al final, a los salvadoreños $u$ otra persona receptora de mensajes, creerán que los medios nos están transculturizando o mal educando a los ciudadanos. 


\section{Conclusiones}

Los niños se hacen obesos, inconformes con el tipo de vida, adictos a consumir más horas de las debida en ver televisión, buscan mil y una manera de perder el tiempo con los aparatos electrónicos para jugar entre videojuegos y redes sociales. Las mujeres prefieren ser amas de casa pero acompañadas con las telenovelas y programas de chambres.

Los televidentes adultos se la pasan hipnotizados viendo una y otra vez el mismo programa de fútbol, así lo hacen los niños con programas tóxicos para su salud mental.

Los medios de comunicación deben regular su programación, ya se ha discutido ese punto, no deben hacer caso omiso y estar transmitiendo mensajes perjudiciales especialmente para la niñez.

Los adolescentes se la pasan conectados a internet, más en las redes sociales, haciendo del ocio el amigo número uno. ¿Hasta qué punto seguirán siendo los medios de comunicación los protectores o los súper héroes de una sociedad con problemas, hipnotizada por la información que lanzan los MCS?

Los medios de comunicación tendrían que tener elementos primordiales en su misión y visión, de encaminar a construir sociedades pensantes, con cierto grado cultural. No queremos sociedades estereotipadas, sin valores o con una visión de títere ante los medios de comunicación social.

Los medios de comunicación salvadoreña, no cuentan con un formato establecido en su programación, sus programas elaborados, son anticulturales, con bajo léxico y no invocan a aspectos intelectuales.

Las funciones de los medios de comunicación no se cumplen en El Salvador, ya que, el entretenimiento y ocio, son los primeros lugares. Su programación adolece de programas culturales o científicos.

La mayoría de programas son "enlatados", son pocos los que se producen, empero, con formatos de televisión mejicana: Televisa y TV Azteca. 
Los programas que se realizan en El Salvador, reflejan el tipo de cultura de los salvadoreños. Ventana que degrada la imagen del país. Excepto aquéllos programas que en cierta medida ayuden a fomentar valores, espiritualidad o aspectos educativos.

El objetivo primordial de los Medios de Comunicación Social es mantener el rating y, no les importa el grado cultural que puedan trasmitir sus programas. Al final, la sociedad es la que tendrá su recompensa, ya sea con programas positivos o con antivalores.

Tanto el Gobierno de la República de El Salvador, el Ministerio de Educación y Ministerio de Gobernación, tienen que vigilar la programación y publicaciones en los medios de comunicación. Vivimos en democracia, con libertad de expresión, pero debemos cuidar, en especial, la salud mental de los niños.

Los medios de comunicación social, tienen la obligación de producir más programas culturales, tienen que analizar que, a través de los MCS, se puede sensibilizar con mensajes más creativo, cultural y educativo. El receptor está dispuesto a consumir programación de calidad, empero, si se le muestran mensajes negativos, al final así serán sus comportamientos y efectos.

\section{Bibliografía}

Encuesta (2005): realizada a alumnos de colegios en la ciudad de Santa Ana, El Salvador. Universidad Francisco Gavidia.

Fernández García, Tomas; García Rico (2001): Agustín. Medios de Comunicación, Sociedad y Educación. Ediciones de la Universidad de Castilla. España. En: books.google.com.sv/books?isbn $=8484270769$

Frasca, Gonzalo (2012): Opinión. Los videojuegos violentos ¿pueden provocar masacres reales?, CNN en español. En: http://cnnespanol.cnn.com/2012/07/20/opinion-losvideojuegos-violentos-pueden-provocar-masacres-reales/

Gómez, Wilmer (2012): periodista salvadoreño y catedrático de comunicaciones Universidad Francisco Gavidia.González Torres, Julián (2012): Tony Saca: sentimiento y nación. Diario digital Contra Punto. 
Lemus, Karen y otros (2012). Estudiantes de Relaciones Públicas y Comunicaciones. Universidad Francisco Gavidia.

Rincón, Omar, Observatorios de Medios, Universidad Nacional del Centro de la Provincia de Buenos Aires, p. 16 En: http://es.scribd.com/doc/75058309/intersecciones-encomunicacion-n\%C2\%BA5

Ticas, Pedro (2012): Antropología económica del consumo y consumismo salvadoreño, Diario CoLatino.

En: http://www.diariocolatino.com/es/20121211/articulos/110710/Antropolog\%C3\%ADaecon\%C3\%B3mica-del-consumo--y-consumismo-salvadore\%C3\%B10.htm

Urquiza, Waldemar. Los Medios de Comunicación Social en El Salvador. Cientista social. En: http://www.youtube.com/watch?v=ildjG5vHpds

http://www.laprensagrafica.com/el-salvador/social/237543-conasida-oficializa-no-meetiquetes.html 16 de diciembre del 2011

http://www.laprensagrafica.com/el-salvador/social/237543-conasida-oficializa-no-meetiquetes.html 16 de diciembre del 2011

http://www.youtube.com/watch?v=SBuKuA9nHsw\&feature=player_embedded 20 de junio del 2012

http://www.youtube.com/watch?v=gs6E-PibUec\&feature=relmfu 20 de junio del 2012 http://archivo.elfaro.net/Secciones/El_Agora/20040823/EIAgora1_20040823.asp 23 agosto del 2004

http://www.elmundo.es/elmundo/2007/05/28/comunicacion/1180352350.html 28 de mayo del 2007

http://books.google.com.sv/books?id=P2bCqrT_NP0C\&pg=PA57\&dq=Los+medios+de+comu nicacion+y+su+incidencia\&hl=es\&sa=X\&ei=c7uVT9SnGsbf0QHtjvHmBw\&ved=0CDIQ6A EwAAhttp://www.youtube.com/watch?v=ildjG5vHpds

http://www.starchannel.com.sv/internettv/player.php+

http://www.youtube.com/watch?v=AiFXSI8OnU0

http://www.facebook.com/fidel.lopezeguizabal 
http://www.miradio.com.sv/scan/

http://aristeguinoticias.com/0412/kiosko/prohibiran-el-reggaeton-por-vulgar-y-mediocre-encuba/

http://www.youtube.com/watch?v=WGb8hUgZ0zc

http://archivo.elfaro.net/Programas/Imprimir/Imprime_Pagina.asp?UrlLocal=/secciones/el_ago ra/20040823/elagora1_20040823.asp

http://m.laprensagrafica.com/2011/12/16/conasida-oficializa-\%E2\%80\%9Cno-meetiquetes\%E2\%80\%9D-2/

\section{Notas}

[1] En Cuba, prohibieron enfáticamente el Reggaeton, por ser un tipo de música vulgar y mediocre. Las letras de las canciones hablan sobre relaciones sexuales, malas palabras y palabras soeces. Véase en http://aristeguinoticias.com/0412/kiosko/prohibiran-el-reggaetonpor-vulgar-y-mediocre-en-cuba/

[2] La Televisión Educativa Salvadoreña canal 10, sufrió una transformación debido a los cambios de Gobierno, anteriormente eran dos canales: canales 8 y 10, sin embargo, se vendió una frecuencia a la Asociación AGAPE de El Salvador. A pesar de ser el canal que pertenece al estado, no tiene el impacto esperado. Véase en http://archivo.elfaro.net/Programas/Imprimir/Imprime_Pagina.asp?UrILocal=/secciones/el_ago ra/20040823/elagora1_20040823.asp

\section{Forma de citar este artículo en bibliografías}

Fidel Arturo López Eguizábal (2013): "Medios de Comunicación en El Salvador, entre transculturizaciones y programación con antivalores", en Revista PANGEA, 4, páginas 25 a 68. Red Académica Iberoamericana de Comunicación. Recuperado el de de 2 de: http://www.revistapangea.org 